\title{
Transforming Growth Factor- $\beta$ Signaling Strength Determines Target Gene Expression Profile in Human Keratinocytes
}

\author{
A. Kareddula*, , E. Zachariah ${ }^{2}$, D. Notterman ${ }^{2,3}$ and M. Reiss ${ }^{*, 1,3}$ \\ ${ }^{I}$ Department of Internal Medicine, ${ }^{2}$ Department of Pediatrics and ${ }^{3}$ Department of Molecular Genetics, Microbiology \& \\ Immunology, UMDNJ-Robert Wood Johnson Medical School and The Cancer Institute of New Jersey, New Brunswick, \\ $N J, U S A$
}

\begin{abstract}
Transforming Growth Factor- $\beta$ (TGF $\beta$ ) maintains keratinocyte homeostasis, and induces epithelial-tomesenchymal transition (EMT) in response to tissue injury. To investigate how these two TGF $\beta$ responses might become uncoupled during malignant transformation, we examined the TGF $\beta$-regulated gene expression programs and cellular responses in human keratinocytes as a function of TGF $\beta$ type I receptor (T $\beta$ R-I) kinase activity and TGF $\beta$ level. The TGF $\beta$ mediated homeostatic gene response program and cellular growth arrest were extremely sensitive to a reduction in receptor kinase activity, while much stronger inhibition of TGF $\beta$ receptor activity was needed to inhibit the tissue injury response gene expression program and EMT. Both endogenous TGF $\beta$ and high exogenous levels of TGF $\beta$ induced the homeostatic response, while only high levels of TGF $\beta$ induced EMT. These results suggest that a reduction in receptor signaling activity may be sufficient for keratinocytes to escape from TGF $\beta$ 's tumor suppressor function, while higher levels of TGF $\beta$ associated with tumor progression are pro-invasive/metastatic. These findings have important implications for the optimal use of TGF $\beta /$ Smad signaling antagonists as anti-cancer therapeutics.
\end{abstract}

\section{INTRODUCTION}

The $25 \mathrm{kDa}$ dimeric polypeptide Transforming Growth Factor- $\beta$ (TGF $\beta$ ) regulates a wide range of cellular processes and plays an important role in cancer development and progression [1]. TGF $\beta 1$ binds primarily to the type II receptor (TRR-II), followed by the recruitment of the type I receptor (TßR-I, Alk-5) into a heterotetrameric complex with two T $\beta R$-II molecules and a single TGF $\beta$ dimer (see [2] for review). Once this ternary complex forms, the T $\beta R$-II kinase activates the T $\beta R$-I serine-threonine kinase. In most cell types, this is the key step in transducing all of TGF $\beta$ signals, thus positioning T $\beta R$ R-I as the gatekeeper of the TGF $\beta$ signaling pathway $[2,3]$. The activated T $\beta R$-I receptor kinase (Alk-5) phosphorylates two Smad proteins, Smad2 and Smad3 $[4,5]$, which then form heteromeric complexes with the common mediator Smad, Smad4 that accumulate in the nucleus [6-9] and initiate the TGF $\beta$ target gene expression program $[10,11]$.

In normal epithelia, Transforming Growth Factor- $\beta$ (TGF $\beta$ ) plays a key role in maintaining tissue homeostasis by inducing cell cycle arrest, differentiation and apoptosis, and ensuring genomic integrity [1]. In this manner, TGF $\beta$ functions as a tumor suppressor. In addition, TGF $\beta$ orchestrates the response to tissue injury and mediates repair by inducing epithelial to mesenchymal transition (EMT), and by increasing cell motility and invasiveness in a time- and space-limited manner. Escape from TGF $\beta$ 's tumor suppressive actions appears to be an early and frequent event in carcinogenesis [1]. While tumor cells are generally refractory to

*Address correspondence to these authors at the Department of Molecular Genetics, Microbiology \& Immunology, UMDNJ-Robert Wood Johnson Medical School and The Cancer Institute of New Jersey, New Brunswick, NJ, USA; E-mail: reissmi@umdnj.edu; kareddap@umdnj.edu
TGF $\beta$-mediated growth arrest, many retain other functions involved in tissue repair such as EMT and migration [12]. In this case, the TGF $\beta$ pathway acts in a pro-oncogenic manner to promote the invasive and metastatic tumor phenotype. Even though this uncoupling of the two arms of the TGF $\beta$ effector pathway frequently occurs in cancer, the underlying molecular mechanisms have remained elusive $[13,14]$.

Surprisingly little is known about how the two fundamentally different responses to TGF $\beta$ are regulated. In principle, response specificity could be controlled at several different levels, including ligand concentration, receptor availability, receptor kinase activity or Smad activation [2]. As the T $\beta R$-II kinase is constitutionally active, the level of T $\beta R$ II expression and the degree of receptor heterodimerization determine T $\beta R$-I activity. Thus, the level of T $\beta R$-I kinase activity appears to be the key variable that controls most if not all of the downstream signaling events [15]. While genetic inactivation of TGF $\beta$ receptors or Smads that result in complete loss of all TGF $\beta$ responsiveness in cancer is rare, significant reductions in TRR-II expression are commonly found human cancers, including HNSCC and small cell lung cancer [16-20]. On the other hand, advanced cancers are frequently associated with constitutively high levels of biologically active TGF $\beta$, which appears to contribute to the neoplastic phenotype (reviewed in $[1,12])$. In order to reconcile these two seemingly paradoxical events, we wished to test the hypothesis that a reduction in receptor signal strength might alter the pattern of cellular responses to TGF $\beta$ in a way that allows cells to escape from its tumor suppressive actions, while, in this context, an increase in ligand level might facilitate EMT, invasion and metastasis.

To test this hypothesis, we made use of potent and selective chemical inhibitors of the T $\beta R$-I kinase, which allowed us to conduct precisely controlled T $\beta R$-I activity "knock- 
down" experiments [21, 22]. We have shown previously that these agents are capable of inhibiting TGF $\beta$-mediated Smad phosphorylation, target gene expression, cell cycle arrest, EMT, and cell motility in a dose-dependent manner [22, 23]. In addition, in order to simulate the switch from a low to a high TGF $\beta$ producing state, we carried out these experiments under basal conditions of "endogenous" TGF $\beta$ signaling as well as in the presence of exogenously added TGF $\beta$. We found that TGF $\beta$-mediated growth arrest is much more readily disrupted by even a modest reduction in TRR-I kinase activity, while blocking TGF $\beta$-induced EMT requires a much greater degree of receptor inhibition. Secondly, we found that the TGF $\beta$-regulated gene expression program encompasses three distinct sets of genes. The first set is induced/repressed at any level of TGF $\beta$, regulates tissue homeostasis, and is exquisitely sensitive to a reduction of T $\beta \mathrm{R}-$ I kinase activity. A second set of genes that are primarily involved in development are also induced/repressed at any level of TGF $\beta$, but resistant to partial T $\beta$ R-I blockade. Finally, a third set of genes is engaged only by exogenously added high concentrations of TGF $\beta$, and also relatively resistant to T $\beta$ R-I blockade. Most of the genes in the latter group come into play in response to stress and tissue injury. These findings predict that cancer-associated reductions in $T \beta R$ receptor expression levels on the one hand, and increases in tumor-associated bioactive TGF $\beta$ on the other are likely to each have a distinct impact on the cellular responses to TGF $\beta$. Moreover, these findings have important implications for the design and optimal application of TGF $\beta$ pathway targeting agents that are under clinical development [24].

\section{MATERIALS AND METHODOLOGY}

\section{Cell Culture}

HKc/HPV16 d-1 human papilloma virus type 16immortalised keratinocytes (obtained from Dr. L. Pirisi, University of South Carolina, Columbia, SC) were maintained in enriched MCDB 153 medium as described by Pirisi et al. [25] and supplemented with 1\% (v/v) FBS (MCDB $\left.153^{++}\right)$.

\section{Western Blot Analysis}

Cell lysates were prepared, resolved by SDS-PAGE and transferred to nitrocellulose membrane as previously described [23]. Total Smad2 was detected using a rabbit polyclonal anti-Smad2 antibody (Zymed ${ }^{\mathbb{B}}$ Laboratories Inc., South San Francisco, CA). Phospho-Smad2 (pSmad2) was detected using our own rabbit polyclonal anti-pSmad2 antibody as previously described [26]. Jagged1 and CTGF were detected with rabbit anti-Jagged1 (sc-8303) and goat antiCTGF (sc-14939) from Santa Cruz Biotechnology (Santa Cruz, CA). Smad7 was detected using a rabbit polyclonal anti-Smad7 antibody from Abcam Inc. (Cambridge, MA). CDKN1A was detected using a mouse monoclonal antibody against the human $\mathrm{p} 21^{\mathrm{WAF} 1}(\mathrm{Ab}-1)$ from Calbiochem Novabiochem Corp. (San Diego, CA).

\section{Detection of F-Actin}

Cells were plated in chamber slides and allowed to adhere overnight. Following treatment with TGF $\beta$ (100 pM), SD-093 $(1 \mu \mathrm{M})$, TGF $\beta$ plus inhibitor, or vehicle only for 72 h, F-Actin was detected using Alexa Fluor 488 Phalloidin
(Molecular Probes, Eugene, OR) as previously described [22].

\section{Gene Expression Profiling}

For gene expression profiling, medium was aspirated and cell cultures were washed with ice-cold PBS, followed by RNA extraction using the RNeasy Midi kit (Qiagen) using the on-column DNase I digestion option. RNA was eluted into RNase free water and quantified. The concentration was adjusted to $1 \mu \mathrm{g} / \mu 1$ and quality assessed on an RNA chip using an Agilent 2100 Bioanalyzer (Agilent Technologies, Palo Alto, CA). Isolated total RNA was processed as recommended by Affymetrix, Inc. (Santa Clara, CA). In brief, cDNA was synthesized from the total RNA using the SuperScript ${ }^{\circledR}$ Double Stranded cDNA Synthesis kit (Invitrogen Corp., Carlsbad, CA) and T7 Oligo (dT) primers. Using the double stranded cDNA as template, biotin labeled cRNA was generated by in vitro transcription (IVT) using the BioArray ${ }^{\mathrm{TM}}$ HighYield ${ }^{\mathrm{TM}}$ RNA Transcript Labeling Kit (T7) (Enzo Life Sciences, Inc., Farmingdale, NY). The cRNA was fragmented to 35-200 bases length using Affymetrix protocols and hybridized to the HG-U133 AB GeneChip ${ }^{\circledR}$ set at $45^{\circ} \mathrm{C}$ for 16 hours in an Affymetrix GeneChip ${ }^{\circledR}$ Hybridization Oven 320. The HG-U133 AB GeneChip ${ }^{\circledR}$ set comprises two microarrays containing over $1,000,000$ unique oligonucleotide features covering more than 39,000 transcript variants representing greater than 33,000 wellsubstantiated human genes. Each GeneChip ${ }^{\circledR}$ was then washed and stained with Streptavidin-Phycoerythrin conjugate (SAPE; Invitrogen Corp.) using an Affymetrix Fluidics Station 400 and scanned on a GeneArray laser scanner (Agilent Technologies).

\section{Data Analysis}

Scanned image files were analyzed using the Microarray Suite 5.0 software (MAS 5.0, Affymetrix, Inc.). Scaling and normalization were carried out using the 100 Normalization Control probe set included on the HG-U133 AB chip set. The Wilcoxon's Signed Rank test was used for pairwise comparisons of expression signals between chips, using a pvalue of 0.0025 as cutoff for significant change. Integrated mRNA expression changes represented by the area under the mRNA level-time curve from time zero to 4 hours were estimated using the linear trapezoidal method [27]. The Gene Ontology (GO) database [28] is widely accepted as the standard for vocabulary describing the biological process, molecular function, and cellular component for genes. The NetAffxGene Ontology Mining Tool was used to map GeneChip ${ }^{\circledR}$ probe sets to these hierarchical vocabularies $[29$, 30].

\section{Quantitative RT-PCR}

The QuantiTect ${ }^{\mathrm{TM}}$ Probe RT-PCR Kit (Qiagen) was used for real-time quantification of individual mRNAs. For the PCR, $50 \mu 1$ reaction mixes contained 100 ng of RNA, 0.4 $\mu \mathrm{M}$ primer, $0.2 \mu \mathrm{M}$ dual labeled probe, $0.5 \mu \mathrm{l}$ of QuantiTect Reverse Transcriptase Mix and QuantiTect Probe RT-PCR Master Mix. qRT-PCR was performed using the Mx4000 ${ }^{\circledR}$ Multiplex Quantitative PCR System (Stratagene), with each data point assayed in triplicate. TGF $\beta$ target genes examined included $C T G F, G A D D 45 B, I D-1 H, M A D H 7, T B X 3, S E R-$ PINE1. $\beta$-ACTIN and GAPDH were used as reference genes. 
The following primers and probes were used: $\boldsymbol{C T G F}$ : Forward: 5' GCAGGCTAGAGAAGCAGAGC, Reverse: 5' ATGTCTTCATGCTGGTGC AG, Probe 5'-FAM-TGCGA AGCTGACCTGGAAGAGAACA-BHQ-3', GADD45B: Forward: 5' GGGTGTACGAGTCGGCCAA, Reverse: 5' TGGCCAAGAGGCAGAGGA, Probe 5'-FAM-TTGATGA ATGTGGACCCAGACAGCGTG-BHQ-3', $\boldsymbol{I D - 1 H :}$ Forward: 5' ACG ACA TGA ACG GCT GTT ACT CAC, Reverse: 5' TGTAGTCGATGACGTGCTGGAGAA, Probe 5'FAM-AACCGCAAGGTGAGCAAGGTGGAGA-BHQ-3', MADH 7: Forward: 5' GACGCTGTTGGTACACAAGG TGTT, Reverse: 5' TGCATAAACTCGTGGTCATTGGGC, Probe 5'-FAM-AAGGCTTTCGACTACGAGAAGGCGTABHQ-3', $\boldsymbol{T B} \boldsymbol{X} 3$ : Forward: 5' TGGCGTGGTTTATATGTC CGGGAT, Reverse: 5' AATCCGCACTGAGGGAGATG TCTT, Probe 5'-FAM-AAACGTCGGTTGCATTGAGCT ACTGG-BHQ-3', SERPINE1: Forward: 5' TGCTGGTG
AATGCCCTCTACTTCA, Reverse: 5' AGAGACAGTGCT GCCGTCTGATTT, Probe: 5'-FAM-ACGGCCAGTGGAA GACTCCCTT-BHQ-3', $\boldsymbol{\beta}$-ACTIN: Forward: 5' TCAGCAAGC AGGAGTATGACGAG, Reverse: 5' ACATTGTG AACTTTGGGGGATG, Probe: 5'-FAM-ACGGTGAAGG TGACAGCAGT-BHQ-3', GAPDH: Forward: 5'-CCACCC ATGGCAAATTCC, Reverse: 5'-TCGCTCCTGGAAGATG GTG, Probe- 5'-FAM-TGGCACCGTCAAGGCTGAGAA CGT-BHQ.

\section{RESULTS}

We tested the hypothesis that TGF $\beta$ receptor signal strength determines cellular response specificity using human epidermal keratinocytes as a model system. The potent and selective chemical T $\beta$ R-I kinase inhibitor, SD-093, was used to precisely control T $\beta$ R-I receptor activity. This agent selectively inhibits T $\beta$ R-I (Alk-5), as well as the activin re-
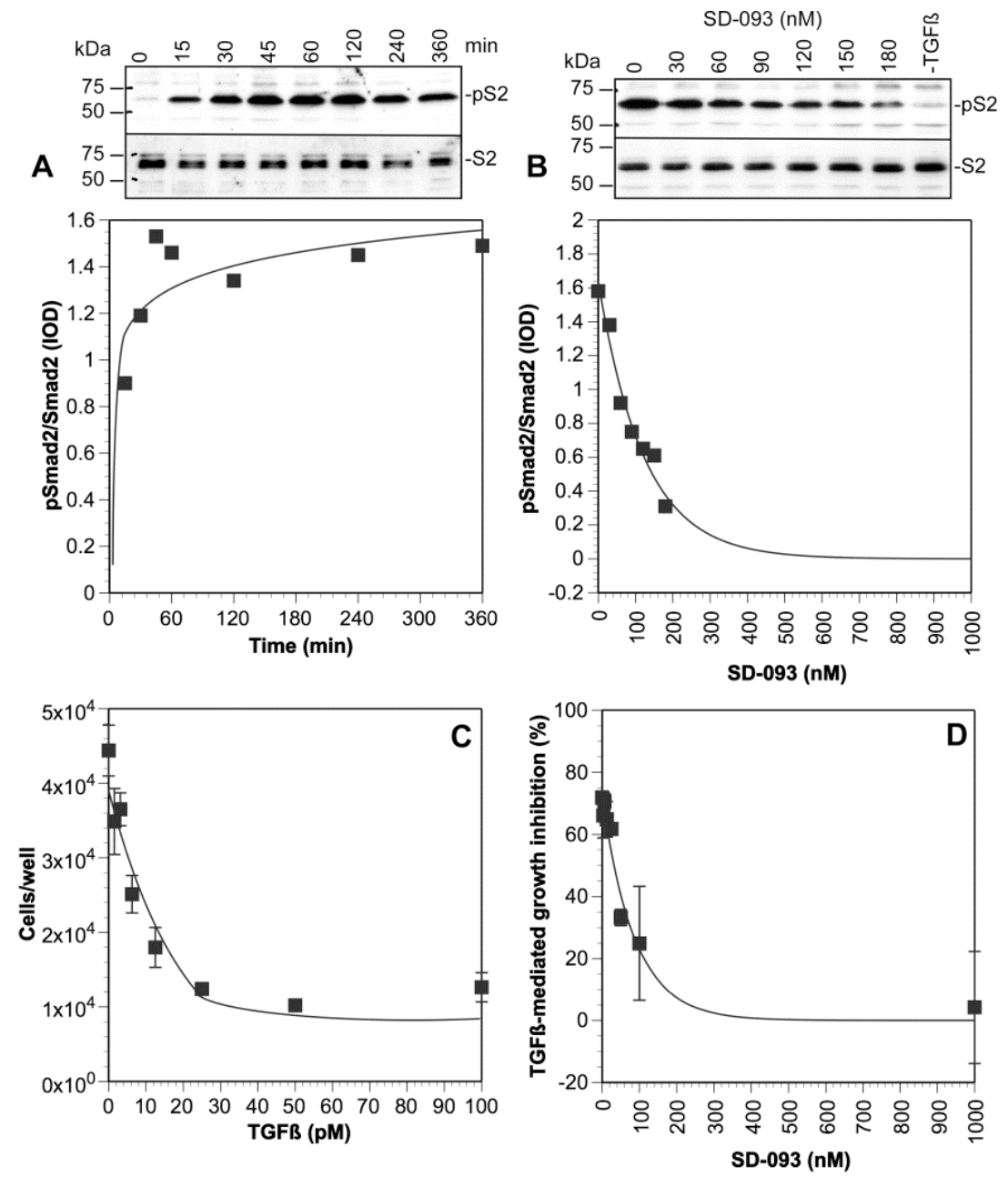

Fig. (1). Effects of Alk-5/T $\beta$ R-I kinase activity on Smad2 phosphorylation and cell proliferation. A. HKc/HPV16 keratinocytes were treated with $100 \mathrm{nM} \mathrm{SD-093}$ for $3 \mathrm{~h}$ to allow complete dephosphorylation of pre-existing pSmad2. Treatment with TGF $\beta 1$ rapidly induced phosphorylation of Smad2, which peaked at 1-2 h, and then gradually declined. B. Pre-treatment of HKc/HPV16 cells with SD-093 blocked TGF $\beta 1$-induced Smad 2 and -3 phosphorylation in a dose-dependent manner with an estimated $\mathrm{IC}_{50}$ of $90 \mathrm{nM}$. pSmad levels were expressed as the ratios of the integrated optical densities of the pSmad over total Smad signals obtained by Western blots. C. HKc/HPV16 cells were plated at 8000 cells/well in 24-well tissue culture plates, treated with TGF $\beta$ at the indicated concentrations or vehicle only, and counted $72 \mathrm{~h}$ later. TGF $\beta 1$ inhibited HKc/HPV16 cell growth in a dose-dependent manner with an $\mathrm{IC}_{50}$ of approximately 5-10 pM, and maximal growth inhibition of $75 \%$. Means and standard deviations of four independent experiments. D. Cells were treated with SD-093 at the indicated concentrations or vehicle only, followed by the addition of TGF $\beta 1$ (100 pM), and counted $72 \mathrm{~h}$ later. SD-093 blocked TGF $\beta 1$ 's growth inhibitory effect in a dose-dependent manner with an $\mathrm{IC}_{50}$ of approximately $50 \mathrm{nM}$, while treatment with SD-093 alone had no significant effect on keratinocyte proliferation. Means and standard deviations of four independent experiments. 
ceptors, Alk-4 and -7, with an $\mathrm{IC}_{50}$ in the low nanomolar range. We have shown previously that T $\beta \mathrm{R}$-I kinase inhibitors block TGF $\beta$-mediated Smad phosphorylation, reporter gene expression, cell cycle arrest, EMT, and cell motility in a dose-dependent manner [22]. Thus, these agents allow us to test whether TGF $\beta$ response specificity varies as a function of T $\beta$ R-I kinase activity. Moreover, cells cultured in the absence of exogenous TGF $\beta$ are apparently exposed to a low level of endogenous TGF $\beta$, as demonstrated by a T $\beta$ R-I kinase-dependent basal level of Smad phosphorylation as well as activation of a TGF $\beta$ responsive reporter gene in cocultured indicator cells [23]. This circumstance allowed us to compare TGF $\beta$ responses under conditions of endogenous signaling to those in cells exposed to high doses of exogenous ligand.

In order to achieve baseline conditions in which TGF $\beta$ signaling was completely shut-off, cells were pre-treated with $1 \mu \mathrm{M}$ of SD-093, which results in rapid dephosphorylation of pre-existing phospho-Smad2 (pSmad2)[8]. $\mathrm{HKc} / \mathrm{HPV} 16$ cells treated with $100 \mathrm{nM} \mathrm{SD-093}$ for $3 \mathrm{~h}$ no longer expressed detectable amounts of $\mathrm{pSmad} 2$ (Fig. 1A, time " 0 "). Under these conditions, treatment of cells with TGF $\beta 1$ rapidly induced phosphorylation of Smad2, which peaked at 1-2 h, and then remained relatively constant for up to $6 \mathrm{~h}$ of continued exposure to TGF $\beta$ (Fig. 1A). Moreover, pre-treatment of HKc/HPV16 cells with SD-093 blocked TGF $\beta 1$-induced Smad2 phosphorylation in a dose-dependent manner with an estimated $\mathrm{IC}_{50}$ of $90 \mathrm{nM}$ (Fig. 1B).

As expected, TGF $\beta 1$ inhibited cell growth of early passage $\mathrm{HKc} / \mathrm{HPV} 16$ in a dose-dependent manner with an $\mathrm{IC}_{50}$ of approximately 5-10 pM, and achieved maximal cell growth inhibition of $75 \%$ (Fig. 1C). As shown in Fig. (1D), treatment with SD-093 blocked TGF $\beta 1$-induced growth inhibition in a dose-dependent manner, with an $\mathrm{IC}_{50}$ of approximately $90 \mathrm{nM}$. Under the conditions chosen for these experiments, treatment with SD-093 alone had no significant effect on keratinocyte proliferation.

The morphological conversion of epithelial cells from their normal epithelioid, cohesive phenotype to a dispersed, fibroblastoid appearance and F-actin stress fiber formation are hallmarks of EMT [31]. As expected, treatment of HKc/HPV16 keratinocytes with exogenous TGF $\beta 1$ resulted in a loss of cell-cell contacts, the acquisition of an elongated and more spindle shaped appearance, and the re-localization of actin filaments from the cell periphery to the cytoplasm (Fig. 2, top row). Treatment of cells with SD-093 alone appeared to increase cell-cell cohesion and to enhance the epithelioid morphology. This was particularly evident at the highest SD-093 concentration (1000 nM) (Fig. 2, left panels). Moreover, treatment of cells with SD-093 was able to block TGF $\beta$-induced EMT in a dose-dependent manner (Fig. $\mathbf{2}$, right panels). However, complete reversal of TGF $\beta$ effects was only seen at the highest doses of SD-093 (1000 nM). Thus, TGF $\beta$-induced induction of R-Smad phosphorylation and inhibition of growth appeared to be significantly more sensitive to T $\beta$ R-I kinase inhibition than the induction of EMT. Of note, similar effects of T $\beta$ R-I kinase inhibition on Smad phosphorylation, cell growth and EMT were obtained using HaCaT human keratinocytes (V. Rajeev and M. Reiss, unpublished observations), thereby practically excluding the possibility that TGF $\beta$ signaling responses were affected by the expression of human papilloma virus genes in HKc/HPV16 cells.

The preceding results suggested that the two major types of cellular responses to TGF $\beta$ (i.e. growth arrest and EMT) might be differentially sensitive to reductions in T $\beta R$-I signaling capability in human keratinocytes. To determine how quantitative differences in T $\beta$ R-I kinase activity might affect cellular responses, we used two different strategies (Fig. 3): First, we compared the effects of dose-dependent inhibition of T $\beta R$-I receptor activity using the SD-093 kinase inhibitor on the gene expression profile induced by a fixed high (receptor saturating) concentration (100 pM) of exogenous TGF $\beta 1$ (Fig. 3A). Secondly, we compared the gene expression profile changes induced by the much lower levels of endogenous TGF $\beta$ with those induced by high levels of exogenous TGF $\beta 1$ (Fig. 3B).

In order to identify the spectrum of keratinocyte genes that are regulated by high levels of TGF $\beta, \mathrm{pSmad} 2$-depleted cells were treated with TGF $\beta 1(100 \mathrm{pM})$ for periods ranging from 0 to 240 minutes and RNA collected for GeneChip ${ }^{\circledR}$ analysis. We identified 730 features that were significantly up- or down-regulated by a factor of $\geq 2$ (SLR $\geq 1)$ at at least two of the four time points $(30,60,120,240$ minutes $)$. To further ensure that we included only changes in gene expression level that were truly mediated by T $\beta R$-I, we excluded
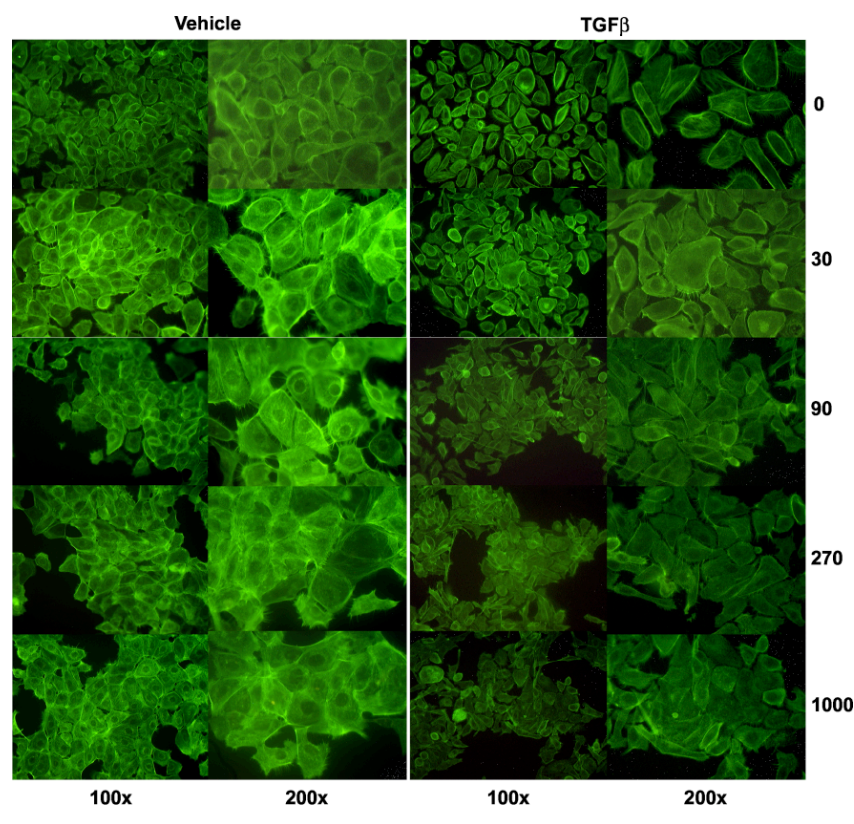

Fig. (2). Effects of Alk-5/T $\beta R-I$ kinase activity EMT. HKc/HPV16 cells were plated in $35 \mathrm{~mm}$ dishes, pre-treated with $100 \mathrm{nM}$ SD-093 for $3 \mathrm{~h}$ to allow complete dephosphorylation of pre-existing pSmad2, and then treated with SD-093 at the indicated concentrations or DMSO only (0), followed by TGF $\beta$ (100 pM) (right two columns) or vehicle only (left two columns) for $48 \mathrm{~h}$. Following fixation, F-actin was detected by phalloidin staining as decribed in "Materials and Methodology". Cells treated with the Alk-5/T $\beta$ R-I kinase inhibitor, SD-093, alone assumed an epithelioid morphology and became even more cohesive than under control conditions. Treatment with exogenous TGF $\beta$ caused cells to disperse, actin stress fibers to form, and cells to assume a more elongated, fibroblastoid morphology. These TGF $\beta$-induced changes were inhibited by SD-093 in a dose-dependent manner. 


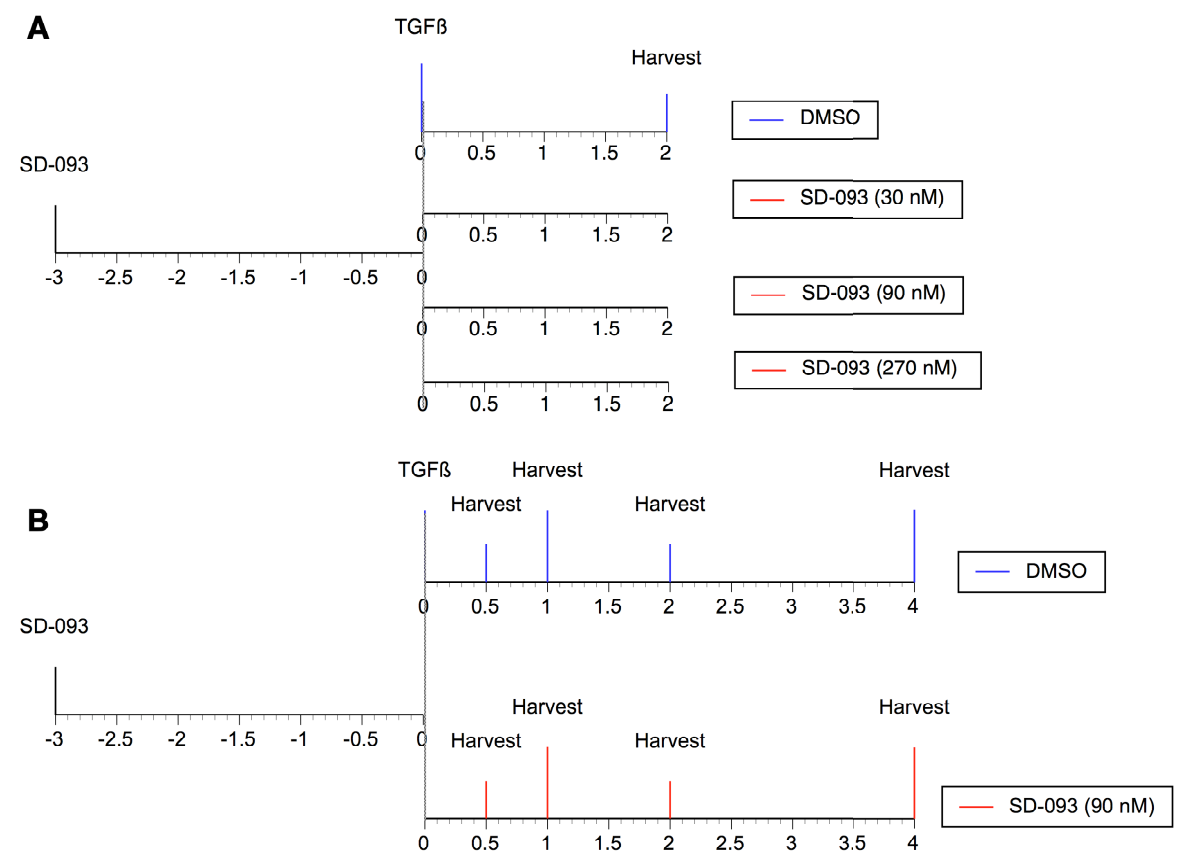

Fig. (3). Experimental design of gene expression profiling studies: $\mathrm{HKc} / \mathrm{HPV} 16 \mathrm{~d} 1 \mathrm{cells}$ were grown in $15 \mathrm{~cm}$ plates to $70-80 \%$ confluency. A. To determine the pattern of TGF $\beta$ regulated genes as a function of receptor kinase activity, cells were treated with either 30,90 , or $270 \mathrm{nM}$ SD-093 or vehicle only, followed by exposure to $100 \mathrm{pM}$ TGF $\beta 1$ for $120 \mathrm{~min}$. Dependence of gene expression on endogenous TGF $\beta$ signaling was ascertained using similar protocols without the addition of exogenous TGF $\beta$. B. To identify the profile of TGF $\beta$ target genes, cells were first depleted of pre-existing pSmads by pretreatment with $0.1 \mu \mathrm{M}$ of the selective Alk-5/T $\beta \mathrm{R}-\mathrm{I}$ kinase inhibitor, SD-093, for 3 hours at $37^{\circ} \mathrm{C}$ followed by 5 washes with $\mathrm{MCDB} 153^{++}$medium containing $10 \mathrm{mg} / \mathrm{ml} \mathrm{BSA}$ and 3 times with $\mathrm{MCDB} 153^{++}$containing $1 \%$ FBS. To determine the effect of half-maximal inhibition of Alk-5/T $\beta$ R-I signaling on the temporal pattern of gene regulation by TGF $\beta$, cells were treated with $90 \mathrm{nM}$ of SD-093 or DMSO only. Fifteen minutes later, recombinant human TGF $\beta 1$ (100 pM; Austral Biologicals) was added for $0,30,60,120$ or 240 minutes.

features for which treatment with $90 \mathrm{nM}$ SD-093 failed to significantly counteract the effect of TGF $\beta$ on the transcript levels at all four time points. This narrowed the set of 730 features down to 235 . Because many genes are represented more than once on the HG-U133AB GeneChip ${ }^{\circledR}$ set, these actually represented 185 unique transcripts. For 157 of these, at least partial biological or molecular function annotation was available (Supplementary Material). Functional classification using the NetAffx Gene Ontology Mining Tool (www.affymetrix.com), revealed that this gene set was significantly enriched for genes encoding both cell-associated and extracellular proteins (Supplementary Material), which included transcription factors, signal transducers, enzymes and enzyme regulators (Supplementary Material). Moreover, as expected, these proteins are predominantly involved in development, regulation of biological processes, cell growth and cellular responses to external stimuli (Supplementary Material).

We then compared the set of transcripts found to be regulated by TGF $\beta$ in human keratinocytes in the current study with those identified in human epithelial cell lines in previously published expression profiling studies of comparable experimental design (Table 1) [32-34]. A total of 92 annotated genes were identified as TGF $\beta$-regulated in at least two of the six studies. These included 51 of the 157 genes identified in the current study. Of note, this analysis may underestimate the degree of overlap, as some of the previous studies made use of earlier generation GeneChips ${ }^{\circledR}$ or custom mi- croarray filters with less extensive coverage of the human genome than the HG-U133AB set used in the present study. Forty-one of the 92 genes had been identified as being regulated by TGF $\beta$ in previous studies but not in ours, possibly because we applied the stringent criterium of T $\beta R$ R-I-kinase dependence. On the other hand, we identified 96 novel genes regulated by exogenous TGF $\beta$ that had not previously been identified as TGF $\beta$ targets (Table $\mathbf{1}$ ).

The vast majority $(88 \%)$ of T $\beta R$-I-regulated transcripts were induced by TGF $\beta$, while the remaining $12 \%$ were repressed (Fig. 4A). Moreover, based on the kinetics of induced mRNA expression changes, these clearly fell into 3 major categories (Fig. 4A, B and Supplementary Material): 76 transcripts were maximally induced or repressed early on following TGF $\beta$ treatment, with a peak change in mRNA expression seen at 30 or 60 minutes, followed by a return to baseline levels. This "early" group was composed of 71 induced (EIG) and 5 repressed (ERG) genes, and included predominantly transcription factors, cytokines or growth factors, as well as MADH7 (SMAD7). A second group of 107 transcripts reached their peak change in expression at $120 \mathrm{~min}$, followed by a return towards baseline by $240 \mathrm{~min}$. This "intermediate" group was composed of 94 induced (IIG) and 13 repressed (IRG) genes, including genes involved in transcription, enzymatic activity and growth factor signaling. The remaining 20 transcripts reached maximal levels at 240 min. This "late" group was composed of 13 induced (LIG) and 7 repressed (LRG) genes, most of which encode 
Table 1. Exogenous TGFß/TßR-I-regulated genes-comparison with published studies. Comparison between 188 gene transcripts found to be regulated by TGF $\beta$ in human keratinocytes in the present study with those identified in human epithelial cell lines in previously published expression profiling studies of similar experimental design [32-34]. Genes identified as TGF $\beta$-regulated in two or more of the six experiments are highlighted $(n=92)$. The majority of these $(n=51 ; 55 \%)$ were also identified as TGF $\beta$ regulated in the current study. In addition, 96 genes were newly identified as TGF $\beta$-regulated in the present study. 1: Current study; 2: Kang et al. (ref. [32]); 3: Zavadil et al. (ref. [33]); 4: Levy et al. (ref. [34]).

\begin{tabular}{|c|c|c|c|c|c|c|c|c|c|c|c|c|c|c|c|}
\hline 7 & & 1 & 2 & 2 & 2 & 3 & 4 & & & 1 & 2 & 2 & 2 & 3 & 4 \\
\hline Probe Set & Gene & HKc & $\mathrm{HaCaT}$ & MCF-10A & HPL1 & $\mathrm{HaCaT}$ & Насат & Probe Set & Gene & HKc & $\mathrm{HaCaT}$ & MCF-10A & HPL1 & HaCaT & HaCaT \\
\hline \multicolumn{8}{|c|}{ Cell Cycle Control } & \multicolumn{8}{|c|}{ Cell Cycle Control } \\
\hline 204908_s_at & BCL3 & $x$ & & & & & & 207826_s_at & ID3 & & $x$ & $x$ & $x$ & $x$ & $\mathrm{x}$ \\
\hline 202284_s_at & CDKN1A & $x$ & $x$ & & $x$ & $x$ & $\mathbf{x}$ & 202431_s_at & MYC & & $\mathbf{x}$ & $x$ & $\mathbf{x}$ & $x$ & \\
\hline 207530_s_at & CDKN2B & & $x$ & & $\mathrm{x}$ & $x$ & $x$ & 211089_s_at & NEK3 & $x$ & & & & & \\
\hline 213524_s_at & GoS2 & $x$ & & & & $x$ & & 204958_at & PLK3 & $\mathrm{x}$ & & & & & \\
\hline 201565_s_at & ID1 & & $x$ & $x$ & $x$ & & & 208078_s_at & SNF1LK & $x$ & & & & & \\
\hline 208937_s_at & \begin{tabular}{|l|l} 
ID2 \\
\end{tabular} & & $x$ & $x$ & $x$ & & $\mathbf{x}$ & & & & & & & & \\
\hline \multicolumn{8}{|c|}{ Negative Feedback of TGF $\beta$ Signaling } & \multicolumn{8}{|c|}{ Negative Feedback of TGF $\beta$ Signaling } \\
\hline & LTBP2 & & & & & $x$ & $\mathbf{x}$ & 212666_at & SMURF1 & $\mathrm{x}$ & & $x$ & $x$ & & $\mathbf{x}$ \\
\hline 206675_s_at & SKIL & $x$ & $x$ & $x$ & $\mathrm{x}$ & $x$ & $\mathbf{x}$ & 205596_s_at & SMURF2 & $x$ & & $x$ & $\mathbf{x}$ & & \\
\hline 204790 at & SMAD7 & $\mathrm{x}$ & $x$ & $x$ & $x$ & $x$ & $\mathbf{x}$ & & & & & & & & \\
\hline \multicolumn{8}{|c|}{ Transcription Factor or Modulator } & \multicolumn{8}{|c|}{ Transcription Factor or Modulator } \\
\hline 202672_s_at & ATF3 & $\mathrm{x}$ & $x$ & $x$ & & $x$ & $\mathbf{x}$ & 202393_s_at & KLF10 & $\mathrm{x}$ & & & & & \\
\hline 201170_s_at & BHLB2 & $x$ & $x$ & $x$ & $x$ & & $\mathbf{x}$ & 208960_s_at & KLF6 & $x$ & & & & & \\
\hline 200920_s_at & BTG1 & $x$ & & & & & & 204334_at & KLF7 & $x$ & & & & $x$ & \\
\hline 228999_at & CHD2 & $\mathrm{x}$ & & & & & & 36711_at & MAFF & $x$ & & & & $x$ & \\
\hline 207980_s_at & CITED2 & $x$ & $x$ & $x$ & $x$ & & $\mathbf{x}$ & 226275_at & MXD1 & $x$ & & & & & \\
\hline 207147_at & DLX2 & $x$ & $x$ & $x$ & $x$ & & & 229396_at & OVOL1 & $x$ & & & & & \\
\hline 206115_at & EGR3 & $x$ & & & & $x$ & & & PBX1 & & & & & $x$ & $\mathbf{x}$ \\
\hline 243748_at & EIF4E3 & $x$ & & & & $x$ & & 209193_at & PIM1 & & $\mathrm{x}$ & & $x$ & $x$ & \\
\hline 244026_at & ELL2 & $x$ & & & & $x$ & & 222238_at & POLM & $x$ & & & & & \\
\hline 241435 at & ETS1 & $x$ & & & & & & 228964 at & \begin{tabular}{|l|} 
PRDM1 \\
\end{tabular} & $\mathbf{x}$ & & & & & \\
\hline 201329_s_at & ETS2 & $x$ & $x$ & $x$ & & $x$ & $\mathbf{x}$ & 212912_at & RPS6KA2 & $x$ & & & & & \\
\hline 209189_at & FOS & $x$ & & & & $x$ & & 202657_s_at & SERTAD2 & & $x$ & $x$ & $x$ & & \\
\hline 202768_at & FOSB & $x$ & & & & $x$ & & 213139_at & SNAI2 & $x$ & & & & & $\mathrm{x}$ \\
\hline 243409_at & FOXL1 & $x$ & & & & & & 201416_at & sox4 & & & $x$ & $x$ & $x$ & $\mathbf{x}$ \\
\hline 203725_at & GADD45A & $x$ & & & & & & 219682_s_at & TBX3 & $x$ & $x$ & $x$ & & & $\mathbf{x}$ \\
\hline \multirow[t]{2}{*}{ 207574_s_at } & GADD45B & $x$ & $x$ & & $x$ & & $\mathbf{x}$ & 201531_at & ZFP36 & $x$ & & & & & \\
\hline & GATA3 & & & & & $x$ & $\mathbf{X}$ & 211965_at & ZFP36L1 & $x$ & & & & & \\
\hline 203394_s_at & HES1 & $x$ & & & & $x$ & $\mathbf{x}$ & 201367_s_at & ZFP36L2 & $x$ & & & & & \\
\hline 221763_at & JMJD1C & $x$ & & & & & & 209431_s_at & ZNF278 & $x$ & & & & & \\
\hline 201466_s_at & JUN & $x$ & & $x$ & $x$ & & $\mathbf{x}$ & 206448_at & ZNF365 & $x$ & & & & & \\
\hline 201473_at & JUNB & $\mathrm{X}$ & $\mathrm{x}$ & & $x$ & & $\mathrm{X}$ & 228005_at & ZXDB & $\mathbf{x}$ & & & & & \\
\hline \multicolumn{8}{|c|}{ Cytokine, Growth Factor or Growth Factor Receptor } & \multicolumn{8}{|c|}{ Cytokine, Growth Factor or Growth Factor Receptor } \\
\hline 221009_s_at & ANGPTL4 & $\mathbf{x}$ & $\mathbf{x}$ & $\mathrm{x}$ & $x$ & & & 203592_s_at & FSTL3 & & $\mathbf{x}$ & & $\mathbf{x}$ & $x$ & $\mathrm{x}$ \\
\hline 205289_at & BMP2 & $\mathrm{x}$ & & & & & & 38037_at & HBEGF & $x$ & & & & & \\
\hline 211518_s_at & BMP4 & & $x$ & & $\mathrm{x}$ & & & 210118_s_at & IL1A & $x$ & & & & $x$ & \\
\hline 210214_s_at & BMPR2 & & & $\mathbf{x}$ & $x$ & $\mathbf{x}$ & & 39402_at & IL1B & $x$ & $\mathbf{x}$ & $x$ & $\mathbf{x}$ & $x$ & \\
\hline 205476_at & CCL20 & $\mathrm{x}$ & & & & & & 206569_at & IL24 & $\mathbf{x}$ & & & & & \\
\hline 205387_s_at & CGB & & $\mathbf{x}$ & $\mathbf{x}$ & $\mathrm{x}$ & & & 205207_at & IL6 & $\mathbf{x}$ & & & & & \\
\hline 210229_s_at & CSF2 & $\mathbf{x}$ & & & & & & 211506_s_at & IL8 & $\mathbf{x}$ & & & & & \\
\hline 209101_at & CTGF & $\mathbf{x}$ & $\mathbf{x}$ & $\mathbf{x}$ & $\mathbf{x}$ & & & 210511_s_at & INHBA & $\mathbf{x}$ & & & & $\mathbf{x}$ & \\
\hline 204470_at & CXCL1 & $\mathbf{x}$ & & & & & & 216268_s_at & JAG1 & $x$ & $x$ & $\mathbf{x}$ & & $\mathbf{x}$ & \\
\hline 209774_x_at & CXCL2 & $x$ & & & & & & 205266_at & LIF & $x$ & & & & $x$ & \\
\hline 207850_at & CXCL3 & $x$ & & & & & & 204200_s_at & PDGFB & $\mathbf{x}$ & & & & $\mathbf{x}$ & \\
\hline \multirow[t]{2}{*}{ 210764_s_at } & CYR61 & $\mathrm{x}$ & & & & & & & PTPRB & & & & & $\mathbf{x}$ & $\mathrm{x}$ \\
\hline & EDN1 & & & & & $x$ & $x$ & 212558_at & SPRY1 & $x$ & & & & & \\
\hline 202023_at & EFNA1 & $x$ & & & & & & 204011_at & SPRY2 & & $x$ & & $x$ & $x$ & \\
\hline 211165_x_at & EPHB2 & & $x$ & $x$ & $x$ & & & 211527 x at at & VEGF & & $x$ & $x$ & $x$ & $x$ & \\
\hline 205767_at & EREG & $\mathrm{x}$ & & & & & & 221029_s_at & WNT5B & & $x$ & & $x$ & & \\
\hline \multicolumn{8}{|c|}{ Signal Transduction Molecule } & \multicolumn{8}{|c|}{ Signal Transduction Molecule } \\
\hline 206170_at & ADRB2 & & $x$ & $x$ & & & & 201829_at & NET1 & $\mathrm{x}$ & & & & $x$ & $\mathrm{x}$ \\
\hline 213039_at & ARHGEF18 & & $x$ & $x$ & & & & 201502_s_at & NFKBIA & $x$ & & & & & \\
\hline 204995_at & CDK5R1 & $x$ & & & & & & 223218_s_at & NFKBIZ & $\mathbf{x}$ & & & & & \\
\hline 224215_at & DLL1 & $x$ & & & & & & 206277_at & P2RY2 & & $x$ & $x$ & $x$ & $x$ & \\
\hline 204794 at & DUSP2 & $x$ & & & & & & 37028 at & PPP1R15A & $x$ & & & & & \\
\hline
\end{tabular}


(Table 1). Contd.....

\begin{tabular}{|c|c|c|c|c|c|c|c|c|c|c|c|c|c|c|c|}
\hline 204472_at & GEM & $\mathbf{x}$ & & & & & & & RDC1 & & & & & $\mathbf{x}$ & $\mathbf{x}$ \\
\hline 205220_at & GPR109B & $x$ & & & & & & 212099_at & RHOB & $\mathbf{x}$ & & & & $x$ & \\
\hline 220901_at & GPR157 & $\mathrm{x}$ & & & & & & 201739_at & SGK & $\mathbf{x}$ & $\mathbf{x}$ & & $\mathbf{x}$ & & \\
\hline 209631_s_at & GPR37 & $\mathrm{x}$ & & & & & & 210001_s_at & socs1 & $\mathbf{x}$ & & & & & \\
\hline 205579_at & HRH1 & $\mathrm{x}$ & & & & & & 203372_s_at & socs2 & $\mathbf{x}$ & & & & & \\
\hline 202068_s_at & LDLR & & & $\mathrm{x}$ & $\mathrm{x}$ & $\mathrm{x}$ & $\mathbf{X}$ & 206359_at & socs 3 & $\mathrm{x}$ & & & & & \\
\hline 216199_s_at & MAP3K4 & & & $\mathbf{x}$ & $\mathrm{x}$ & $\mathbf{x}$ & & 206020_at & socs6 & $\mathbf{x}$ & & & & & \\
\hline 205027_s_at & MAP3K8 & $\mathrm{x}$ & & & & & & 226075_at & SSB1 & $\mathbf{x}$ & & & & & \\
\hline 225344_at & NCOA7 & $\mathrm{x}$ & & & & & & 223746_at & STK4 & $\mathbf{x}$ & & & & & \\
\hline \multicolumn{4}{|c|}{ Extracellular Matrix Component or Modifier } & & & & & \multicolumn{8}{|c|}{ Extracellular Matrix Component or Modifier } \\
\hline 222162_at & ADAMTS1 & $x$ & & & & & & 203936_s_at & MMP9 & $x$ & & & & & \\
\hline 229004_at & ADAMTS15 & $\mathbf{x}$ & & & & & & 205479_s_at & PLAU & $\mathrm{x}$ & & $\mathbf{x}$ & $\mathbf{x}$ & & \\
\hline 219634_at & CHST11 & $\mathbf{x}$ & & & & & $\mathbf{X}$ & 211924_s_at & PLAUR & $x$ & & & & & \\
\hline 211981_at & COL4A1 & & & $x$ & $x$ & $x$ & $\mathbf{x}$ & 204614_at & SERPINB2 & $\mathbf{x}$ & & & & & \\
\hline 235629_at & FN1 & $x$ & & & & $x$ & & 202628_s_at & SERPINE1 & $x$ & $x$ & $x$ & $x$ & $x$ & \\
\hline 230372_at & HAS3 & $x$ & & & & & & 236599_at & SERPINE2 & $x$ & & & & & \\
\hline 201389_at & ITGA5 & & $x$ & & $x$ & & & 215599_at & SMA4 & $x$ & & & & & \\
\hline 208083_s_at & ITGB6 & $x$ & $x$ & $x$ & & & $\mathbf{X}$ & 244766_at & SMG1 & $x$ & & & & & \\
\hline 234608_at & LAMA3 & $x$ & & & & $x$ & & & TIMP3 & & & & & $x$ & $\mathbf{x}$ \\
\hline 209270_at & LAMB3 & $\mathbf{x}$ & & & & & & 216005_at & TNC & $x$ & & & & & \\
\hline 207517_at & LAMC2 & $x$ & & & & $x$ & $\mathbf{x}$ & 205807_at & TUFT1 & $\mathbf{x}$ & & & & & \\
\hline \multicolumn{3}{|c|}{ Other or Unknown functions } & & & & & & \multicolumn{3}{|c|}{ Other or Unknown functions } & & & & & \\
\hline 208161_s_at & ABCC 3 & $x$ & & & & & & 227486_at & NT5E & $x$ & & & & & \\
\hline 225557_at & AXUD1 & $x$ & & & & & & 235165_at & PARD6B & $x$ & & & & & $\mathbf{x}$ \\
\hline 210538_s_at & BIRC3 & $x$ & $x$ & $x$ & $x$ & & & 227458_at & PDCD1LG & $\mathbf{x}$ & & & & & \\
\hline 205479_at & CYP1A1 & $x$ & & & & & $\mathbf{x}$ & 227949_at & PHACTR3 & $x$ & & & & & $\mathbf{x}$ \\
\hline 202436_s_at & CYP1B1 & & $x$ & $x$ & & $x$ & & 202880_s_at & PSCD1 & $x$ & & & & & \\
\hline 216060_at & DAAM1 & $x$ & & & & & & 204748_at & PTGS2 & $x$ & & & & $x$ & $x$ \\
\hline 201925_at & DAF & $x$ & & & & $x$ & & 206157_at & PTX3 & $x$ & & & & & \\
\hline \multirow[t]{2}{*}{ 202887_s_at } & DDIT4 & $x$ & & & & & & 218723_s_at & RGC32 & & $x$ & $x$ & $x$ & & \\
\hline & DLC1 & & & & & $x$ & $\mathrm{X}$ & 238909_at & S100A10 & $x$ & & & & & \\
\hline \multirow[t]{2}{*}{ 230229_at } & DLG1 & $x$ & & & & & & 224029_at & SCN11A & $x$ & & & & & \\
\hline & FHL2 & & & & & $x$ & $x$ & & SEMA3C & & & & & $x$ & $\mathbf{X}$ \\
\hline 202081_at & IER2 & $x$ & & & & & & 205856_at & SLC14A1 & $x$ & & & & & \\
\hline 224572_s_at & IRF2BP2 & $x$ & & & & & & 209681_at & SLC19A2 & $x$ & $x$ & & & & \\
\hline 213076_at & ITPKC & $x$ & & & & & & 219257_s_at & SPHK1 & & & $x$ & $x$ & & \\
\hline 201362_at & IVNS1ABP & $x$ & & & & & & 208322_s_at & ST3GAL1 & & $x$ & & $\mathbf{x}$ & & \\
\hline 210119_at & KCNJ15 & $x$ & & & & $x$ & & & TAGLN & & & & & $x$ & $x$ \\
\hline 235857_at & KCTD11 & $x$ & & & & & & 213349_at & TMCC1 & $x$ & & & & & \\
\hline 213680_at & KRT6B & $x$ & & & & & & 2351146_at & TMCC3 & $x$ & & & & & \\
\hline 219181_at & LIPG & $x$ & & & & & $x$ & 217875_s_at & TMEPAI & $x$ & $x$ & & $x$ & & $x$ \\
\hline 242260_at & MATR3 & $x$ & & & & & & 202643_s_at & TNFAIP3 & $x$ & & & & & \\
\hline 205330_at & MN1 & & $x$ & $x$ & $x$ & & & 208296_x_at & TNFAIP8 & $x$ & & & & & \\
\hline 239650_at & NAP5 & $x$ & & & & & & 201008_s_at & TXNIP & $x$ & & $x$ & $x$ & & $x$ \\
\hline 200632_s_at & NDRG1 & $x$ & & & & & & 204881_s_at & UGCG & & $x$ & $x$ & $x$ & $x$ & \\
\hline 202150_s_at & NEDD9 & $x$ & $x$ & $x$ & $x$ & & $x$ & & & & & & & & \\
\hline
\end{tabular}

enzymes and enzyme regulators. Strikingly, the magnitude of transcriptional response, as defined by the change in integrated mRNA expression levels from 0 to $240 \mathrm{~min}$, differed significantly between the three groups of transcripts (Fig. 4C). Specifically, the change in expression caused by exogenous TGF $\beta$ was greatest for the early genes, and then declined, with the late genes displaying the lowest magnitude of change in expression level.

While the set of early genes was significantly enriched for genes involved in development, regulation of biologicalprocesses, cell growth, and cellular responses to external stimuli, such as wounding, this latter subset was not represented in the intermediate or late group. Moreover, late genes were almost exclusively involved in developmental proc- esses, primarily vascular. Differences across the three kinetic categories were highly statistically significant $(p<0.0001$, Chi-squared Test for Independence, Supplementary Material inset).

In order to examine the effects of half-maximal inhibition of T $\beta R$-I kinase activity on each of the successive waves of exogenous TGF $\beta$-regulated genes, parallel cultures were incubated with $90 \mathrm{nM}$ of the T $\beta R-I$ kinase inhibitor, SD-093. For each gene, we then calculated the relative change in integrated mRNA levels caused by half-maximal inhibition of T $\beta$ R-I kinase activity. As shown in Fig. (5A), the expression of early and intermediate genes following the addition of TGF $\beta$ was generally inhibited by $50 \%$ or less. In contrast, the modest reduction in T $\beta \mathrm{R}-\mathrm{I}$ kinase activity had a dispro- 

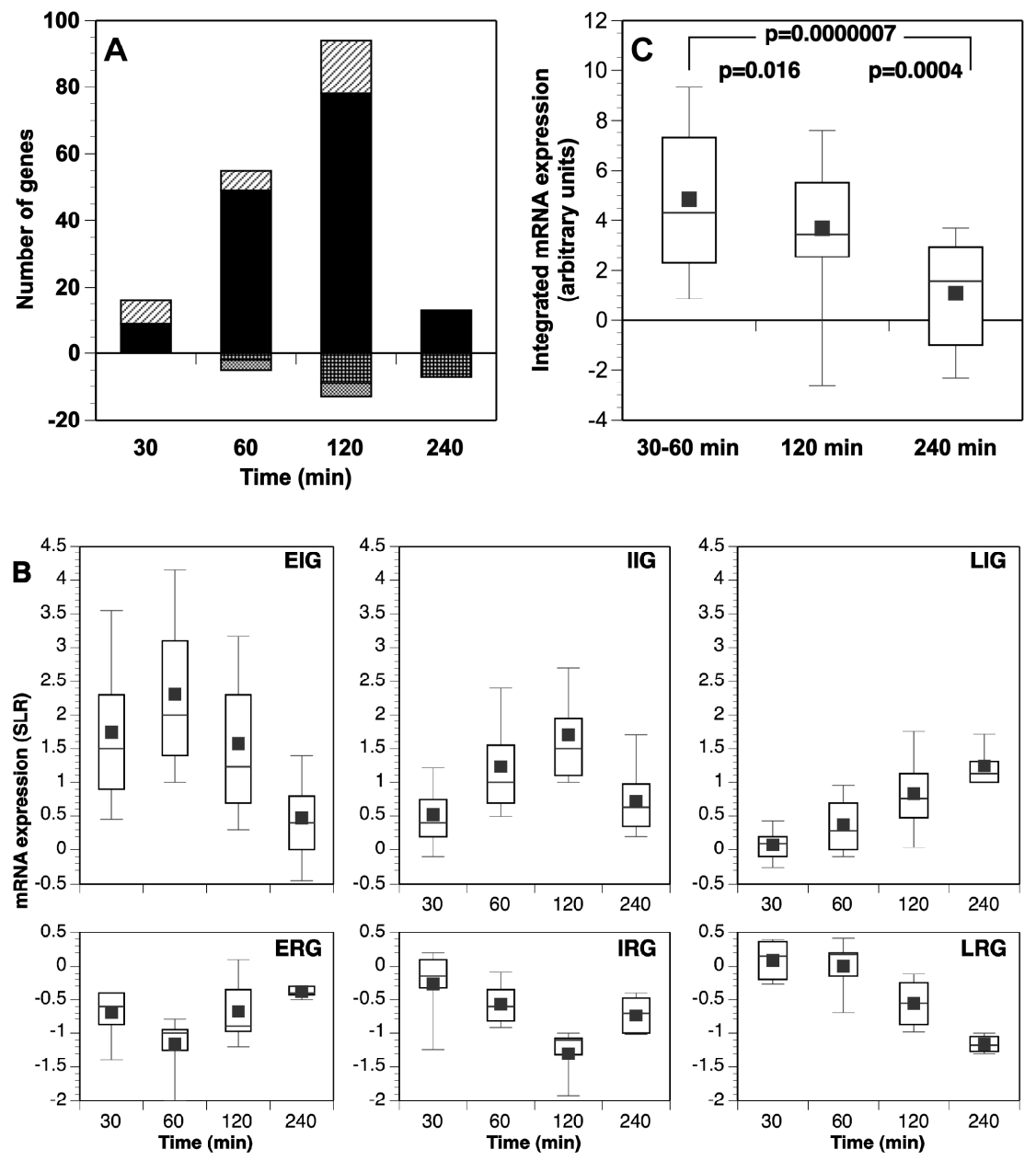

Fig. (4). Kinetics of TGF $\beta$ regulated gene expression. HKc/HPV16 keratinocytes were treated with $100 \mathrm{nM}$ SD-093 for 3 h to allow dephosphorylation of pre-existing pSmad2. Following treatment with TGF $\beta 1$ (100 pM) for 30, 60, 120 or 240 min, RNA was extracted and subjected to U133 Affymetrix GeneChip ${ }^{\circledR}$ gene expression profiling as described in "Materials and Methods". A. Numbers of TGF $\beta 1$ regulated transcripts plotted as a function of the time point at which the mRNA reached its maximum or minimum level. Black and dark grey: Annotated genes. Hatched and light grey: Non-annotated features. B. 76 transcripts were maximally activated (71) or repressed (5) early on following TGF $\beta$ treatment, with peak (or minimal) levels of expression reached at 30 to 60 minutes, followed by a return to baseline mRNA levels (EIG: Early induced gene; ERG: Early repressed gene). The majority of transcripts (107) reached the maximal change in expression at $120 \mathrm{~min}$, followed by a return towards baseline by $240 \mathrm{~min}$ (IIG: Intermediate induced gene; IRG: Intermediate repressed gene). The remaining 20 transcripts reached maximal levels at 240 min (LIG: Late induced gene; LRG: Late repressed gene). SLR: Signal Log Ratio. C. The magnitude of transcriptional response, as defined as the integrated change in mRNA expression levels over time from 0 to 240 min, differed significantly between the three groups of transcripts. Specifically, the change in expression induced by TGF $\beta$ was greatest for the early genes, and then declined, with the late genes displaying the lowest magnitude of change in expression level.

portionately strong impact on the set of late genes. On average, expression of these genes was inhibited by close to $100 \%$. Thus, whereas the early genes appeared to be most strongly induced (or repressed) by exogenous TGF $\beta$ (Fig. 4C), expression of late genes was the most sensitive to inhibition of T $\beta$ R-I kinase activity (Fig. 5A). This progressively stronger effect of partial T $\beta$ R-I kinase blockade on successive waves of target genes would likely result in a qualitative shift in the TGF $\beta$ regulated gene expression program.

Cells cultured in the absence of exogenous TGF $\beta$ produce a low level of endogenous TGF $\beta$, as demonstrated by a T $\beta R$-I kinase-dependent basal level of Smad phosphorylation as well as activation of a TGF $\beta$ responsive reporter gene in co-cultured indicator cells [23]. This allowed us to compare the gene expression profile changes induced by low endoge- nous levels TGF $\beta$ with those induced by the addition of receptor saturating high levels of exogenous TGF $\beta 1$. First, we examined the effects of switching off steady-state endogenous TGF $\beta$ signaling by comparing the gene expression profile of cells that had been maintained in fresh medium for 24 hours with parallel cultures that were treated with $0.1 \mu \mathrm{M}$ SD-093 for the last three hours prior to harvesting. A total of 37 annotated genes underwent a significant change in expression level by SD-093 treatment (Wilcoxon's Signed Rank test, $\mathrm{p}<0.0025$ ) (Supplementary Material). Secondly, we examined the process of reactivating endogenous signaling. In these experiments, cultures pre-treated with $100 \mathrm{nM}$ SD-093 for three hours to deplete pSmads, were exposed to either fresh medium only (endogenous signal activation) or medium with added TGF $\beta 1$ (100 pM) (exogenous signal activation) for $2 \mathrm{hrs}$ in the presence or absence of varying 

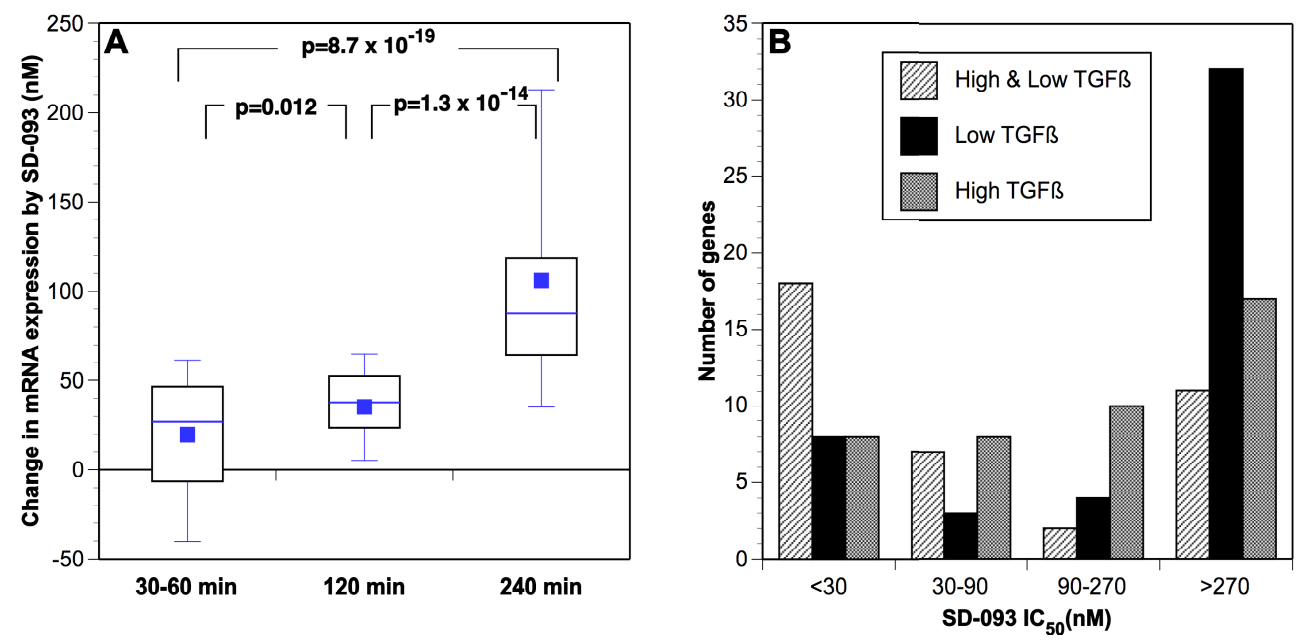

Fig. (5). A. Effects of Alk-5/T $\beta$ R-I kinase activity on exogenous TGF $\beta$-regulated gene expression. In order to examine the effects of halfmaximal inhibition of Alk-5/T $\beta$ R-I kinase activity on the TGF $\beta$-regulated gene expression profile, cultures were incubated with $90 \mathrm{nM}$ of the Alk-5/T $\beta R-I$ kinase inhibitor, SD-093. Changes in mRNA expression levels were estimated by integrating the levels of mRNA over time using the linear trapezoidal method. For each gene, we then calculated the relative change in integrated mRNA levels caused by partial inhibition of Alk-5/T $\beta$ R-I kinase activity. Genes that reached their maximal change at 30 to 60 min. or at 120 min following the addition of TGF $\beta$ were generally inhibited by less than $50 \%$. In contrast, the reduction in Alk-5/T $\beta R$-I kinase activity had its greatest impact on the set of genes that reached their maximal or minimal levels at $240 \mathrm{~min}$. On average, these genes were inhibited by over $50 \%$. Thus, whereas the early genes were most strongly induced (or repressed) by, inhibiting Alk-5/T $\beta$ R-I kinase activity most strongly dampened the regulation of late genes. Thus, the effect of Alk-5/T $\beta$ R-I kinase blockade appears to become amplified in the successive waves of target genes. B. In order to compare the effects of SD-093 on endogenous to those on exogenous TGF $\beta$ signaling, we pre-treated cultures with $100 \mathrm{nM}$ SD-093 for three hours to shut down all active TGF $\beta$ signaling, washed the drug out, and then treated the cells with either fresh medium only (endogenous signaling) or medium to which TGF $\beta 1$ (100 pM) had been added (exogenous signaling) for $2 \mathrm{hrs}$ in the presence of 0, 30, 90, or 270 nM SD-093. SD-093 $\mathrm{IC}_{50}$ for each of the genes estimated from the dose-response curves are shown. The SD-093 $\mathrm{IC}_{50}$ was $\leq 90 \mathrm{nM}$ for approximately two-thirds of genes commonly regulated by low-level (endogenous) and high-level (exogenous) TGF $\beta$ (dose-independent). In contrast, for the majority of genes that were uniquely regulated by either low- or high doses of TGF $\beta$ (dose-dependent), the SD-093 IC 50 was $>90 \mathrm{nM}$ ( $\mathrm{p}=0.0003$, both by Chi-squared Test for Independence and Fisher's Exact Test).

concentrations of SD-093. 73 annotated genes were identified as being either induced or repressed by endogenous TGF $\beta$ (Supplementary Material). In comparison, 79 genes were induced or repressed in parallel cultures treated with exogenous TGF $\beta$ (not shown). Interestingly, only 29 genes were represented in both sets, suggesting major differences in the spectrum of genes regulated by different concentrations of TGF $\beta$. To examine this question in more detail, we merged the sets of genes regulated by turning off or turning on endogenous TGF $\beta$ signaling (Supplementary Material) into a single 89 gene signature, and compared these to the 157 exogenous TGF $\beta$-regulated genes (Supplementary Material). Interestingly, while a signature comprising 38 annotated genes was common to both sets, the majority of genes $(n=51)$ regulated by endogenous TGF $\beta$ were unique. The common signature was significantly enriched for genes involved in epidermal and vascular development, regulation of biological processes, and cell growth (Supplementary Material). In contrast, the set uniquely regulated by high TGF $\beta$ levels was enriched for genes involved in the cellular responses to external stimuli, such as stress, infection and wounding (Supplementary Material). Thus, this latter set comes into play only in cells exposed to high levels of TGF $\beta$. Finally, the 51 genes that were uniquely regulated by endogenous TGF $\beta$ appeared to play a role in development, particularly of the nervous system (Supplementary Material)

To determine whether the genes regulated by different levels of TGF $\beta$ could be distinguished in terms of sensitivity to T $\beta R$-I blockade, we estimated the SD-093 $\mathrm{IC}_{50}$ for each of these genes. As can be seen in Fig. (5B), the SD-093 IC 50 was $\leq 90 \mathrm{nM}$ for approximately two-thirds of genes regulated by either endogenous or exogenous TGF $\beta$ ("high \& low TGF $\beta$ "). In contrast, for the majority of genes that were uniquely regulated by either low endogenous- or high exogenous levels of TGF $\beta$, the SD-093 $\mathrm{IC}_{50}$ was $>90 \mathrm{nM}$ ( $p=0.0003$, Chi-squared Test for Independence). When the gene set was dichotomized between those for which the SD$093 \mathrm{IC}_{50}$ was $\leq 90 \mathrm{nM}$ and $>90 \mathrm{nM}$, the differences were equally significant ( $p=0.0003$, Fisher's Exact Test). These results were entirely consistent with the high sensitivity of late compared to the early- and intermediate TGF $\beta$-regulated genes to SD-093 that we had observed in the independent series of experiments described above.

Microarray-derived gene expression profiling results were validated using quantitative real-time PCR (qRT-PCR) (Fig. 6). RNA generated from an independent time course experiment was used to detect expression of SERPINE1, $C T G F, G A D D 45 B, M A D H 7, T B X 3, I D-1 H$ by quantitative RT-PCR. The expression kinetics detected by qRT-PCR (Fig. 6A) were concordant with those obtained in the microarray experiment (Fig. 6B). In addition, the sensitivity of gene expression to SD-093 as measured by qRT-PCR was highly concordant with that obtained using microarray expression profiling (Fig. 6C). Finally, we examined the effects of TGF $\beta$ and of SD-093 treatment on steady-state levels of some of the proteins encoded by TGF $\beta$ target genes. 

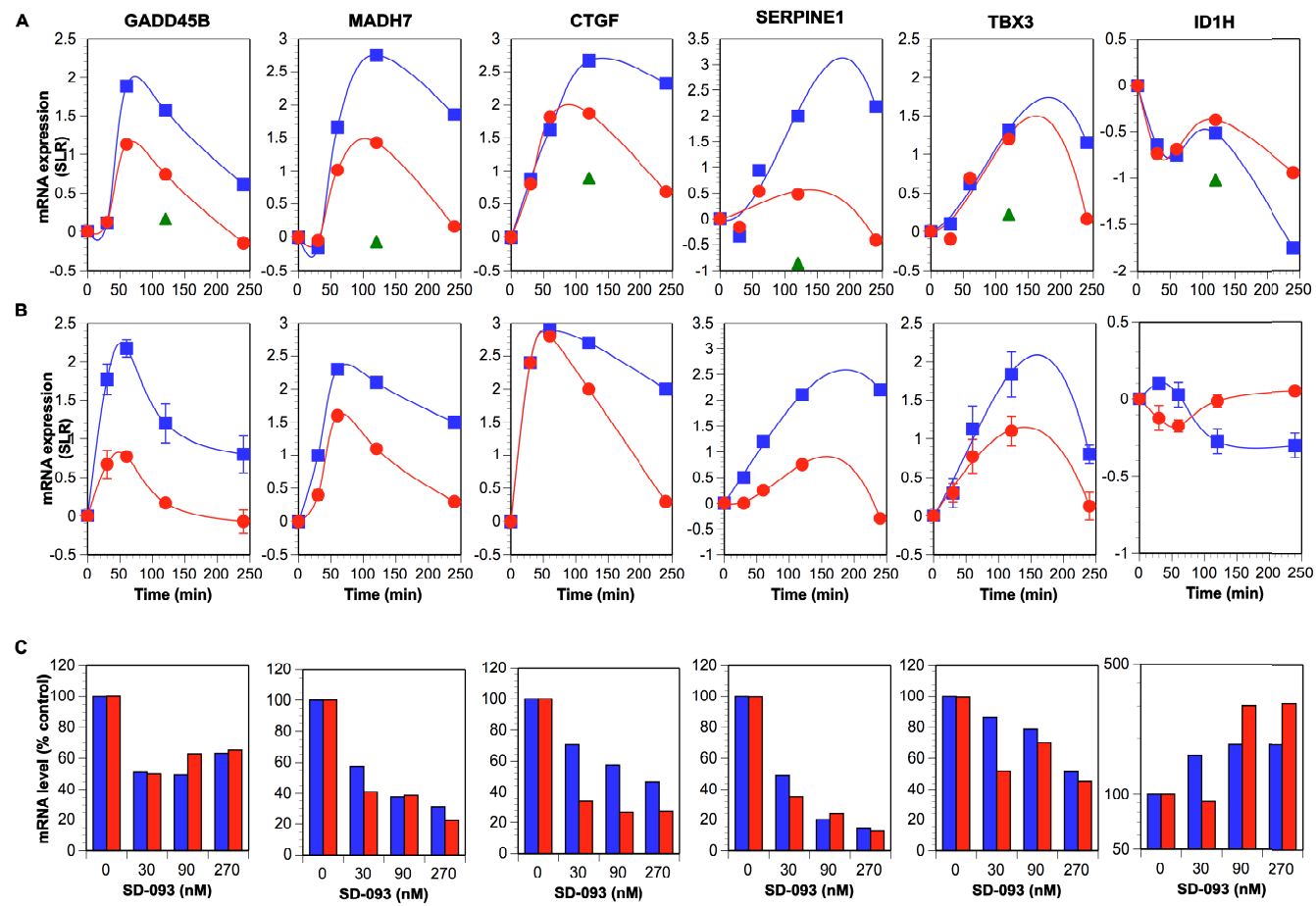

Fig. (6). Validation of microarray expression profiling by qRT-PCR. Kinetics of mRNA expression profiles obtained by quantitative real time PCR for selected genes (A) were concordant with those by GeneChip ${ }^{\circledR}$ analysis (B). Similarly, the sensitivity of mRNA expression levels to SD-093 as measured by qRT-PCR was concordant with similar data obtained by GeneChip ${ }^{\circledR}$ assay (C). Blue bars: qRT-PCR. Red bars: GeneChip ${ }^{\circledR}$.

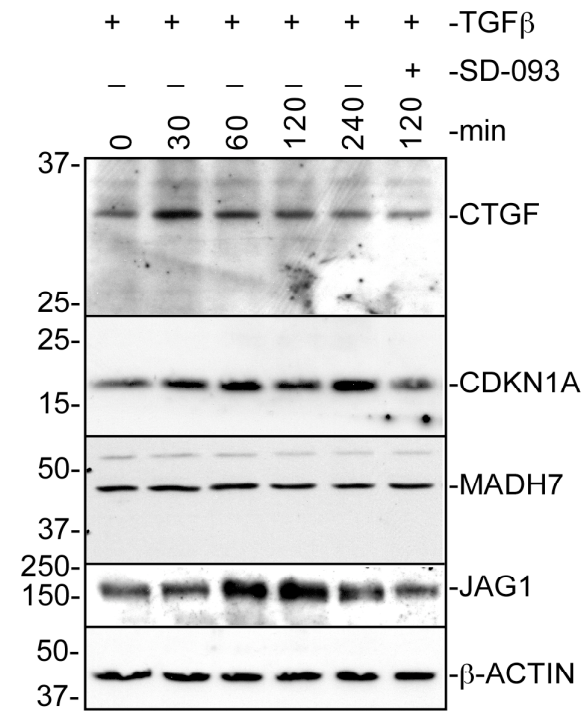

Fig. (7). Validation of microarray expression profiling by Western blotting. HKc/HPV16 cells were pretreated with 100nM SD093 for $3 \mathrm{hrs}$, followed by wash out and treatment with $100 \mathrm{pM}$ TGF $\beta 1$ for the indicated amount of time. Additionally, for the 120 min time point, $90 \mathrm{nM}$ of SD-093 was added 15 minutes prior to the addition of TGF $\beta 1$. Proteins were resolved by SDS-PAGE and detected by Western blotting as described is "Materials \& Methodology". Protein levels were increased by TGF $\beta 1$ treatment and reduced in the presence of Alk-5/T $\beta$ R-I receptor kinase blockade.

As shown in Fig. (7), TGF $\beta$ treatment induced a timedependent increase in the levels of connective tissue growth factor, p21 and Jagged, and these effects were effectively blocked by SD-093. Interestingly, in spite of a brisk induction of MADH7 mRNA induction by TGF $\beta$, the increase of Smad7 protein we observed was rather modest (Fig. 7).

In summary, TGF $\beta$-regulated genes could be classified into three distinct groups (Fig. 8): One set is activated or repressed by both endogenous and exogenous TGF $\beta$ with relatively slow kinetics (late genes, Supplementary Material), and is eliminated from the gene expression program by a modest inhibition $(\leq 50 \%)$ of T $\beta$ R-I kinase activity. These genes appear to be primarily involved in maintaining homeostasis and/or regulating developmental processes (Supplementary Material). In contrast, even when T $\beta$ R-I kinase activity is inhibited by $50-90 \%$, TGF $\beta$ is still capable of regulating a large number of genes. However, under these conditions, the gene expression signature varies considerably as a function of TGF $\beta$ concentration, with minimal to no overlap between the two sets. Thus, under conditions of strong T $\beta$ R-I blockade, endogenous TGF $\beta$ signaling still regulates the expression of genes involved in neural development (Supplementary Material), while high concentrations of TGF $\beta$ predominantly regulate the expression of genes involved in the response to external noxious stimuli (Supplementary Material). The model depicted in Fig. (8) predicts that a reduction in signaling capability of one of TGF $\beta$ 's signaling intermediates (for example, a reduction or loss-of-function mutation of $\mathrm{T} \beta \mathrm{R}$ receptors or Smad proteins) will be associated with a loss of the TGF $\beta$ gene expression signature that mediates its homeostatic (tumor suppressive) function. This may constitute the first major shift in TGF $\beta$ signaling that occurs during carcinogenesis. Moreover, in this context, a subsequent rise in the level of biologically active TGF $\beta$ in the tumor microenvironment will selectively favor the constitutive activation of the gene expression signature associated with cellular 


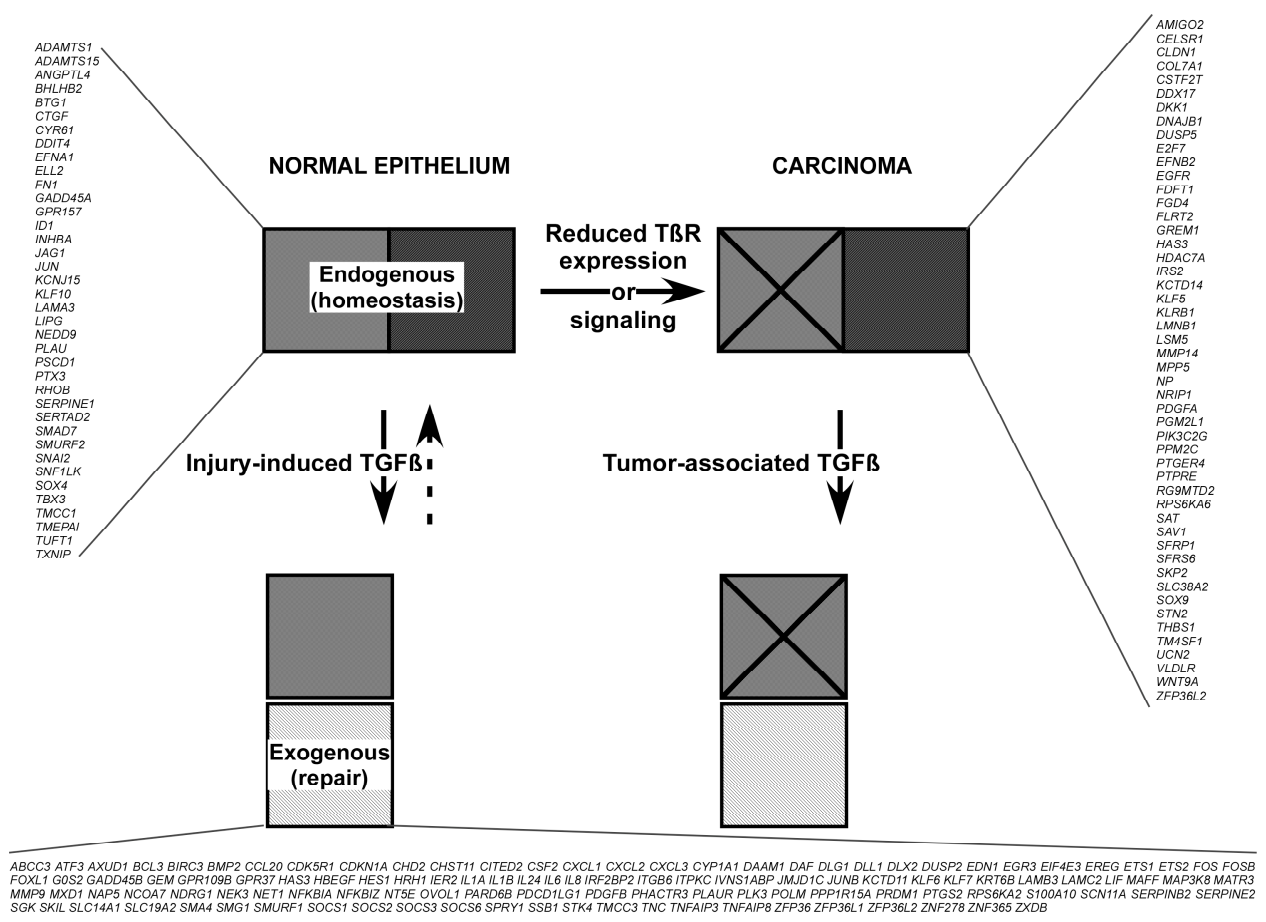

Fig. (8). Model of TGF $\beta / T \beta R$-I-regulated gene expression profiles. In normal epithelium, endogenous TGF $\beta$ regulates approximately 100 genes that control tissue homeostasis listed in the left- and right-hand columns ( $\square+\mathbf{0})$. High concentrations of bioactive TGF $\beta$ generated during tissue injury alter the expression of approximately 150 genes, one third of which are also regulated by endogenous TGF $\beta$ (left hand column, $\square$ ), while the remaining two thirds are uniquely induced/repressed by high concentrations of TGF $\beta$ (bottom panel, $₫$ ). A moderate $(\sim 50 \%)$ reduction in T $\beta \mathrm{R}$ receptor signaling capability (caused by inhibition of receptor kinase activity) abrogates TGF $\beta$ 's ability to induce/repress the common set of genes ( $\square$ ). However, under these conditions, low (endogenous) concentrations of TGF $\beta$ are still capable of regulating the approximately 50 genes listed on the right (圆). Most interestingly, under these same conditions of partial receptor blockade, a

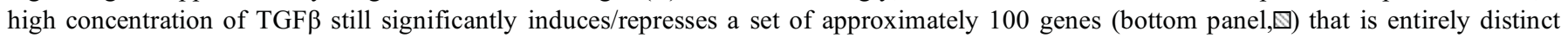
from the endogenous TGF $\beta$-regulated genes shown on the right (洄). This model has several important implications for our understanding of the role of TGF $\beta$ signaling during tumor development. A decrease in receptor expression level or acquisition of a receptor mutation would result in loss of approximately half of the endogenous TGF $\beta$-regulated gene expression program that primarily mediates its homeostatic function ( $\square$ ), while the other half of the gene expression program would remain under TGF $\beta$ control (四). Most of the latter genes are involved in development. If, at a later stage of tumorigenesis, cells become exposed to high concentrations of activated TGF $\beta$, an entirely different secondary gene expression program comes into play $(\mathbb{Q})$. These genes appear to be primarily involved in the cellular response to (noxious) external stimuli and include many genes involved in invasion and metastasis. Thus, this model predicts that the TGF $\beta$ signaling pathway can undergo two distinct shifts during carcinogenesis, each of which is associated with a major change in gene expression profile and, consequently, phenotype. Besides these biological implications, this model also predicts that TGF $\beta$ pathway antagonists that target the intracellular signaling machinery (for example, chemical receptor kinase inhibitors) may alter the cellular gene expression profile and phenotype in ways that are quite distinct from agents that trap excess ligand (for example, neutralizing TGF $\beta$ antibodies). While the former may mimic the effects of lowering receptor expression or receptor mutation, the latter are likely to selectively block the metastasis-associated gene expression profile. As both types of agents are currently undergoing early stage clinical trials, it is important that our findings be taken into consideration in planning their further clinical development.

responses to noxious stimuli (wounding response), which are precisely the ones involved in tumor cell invasion and metastasis [35]. If this model is correct, it predicts that agents that target TGF $\beta$ itself might have a more favorable therapeutic index than molecules that interfere with the intracellular signaling pathway. Specifically, treatment with chemical T $\beta R$ inhibitors may negatively affect epithelial- and vascular homeostasis. Conversely, our results suggest that TGF $\beta$ targeted agents, such as neutralizing antibodies, need to be administered at suffi-ciently high doses to counteract the proinvasive and -metastatic actions of TGF $\beta$.

\section{DISCUSSION}

Our main goal was to test the hypothesis that a reduction in receptor signal strength might alter cellular responses to TGF $\beta$ in ways that allow cells to escape from its tumor sup- pressive actions, while an increase in ligand level might facilitate EMT, invasion and metastasis. This is an important question because both decreases in TGF $\beta$ receptor levels and increases in TGF $\beta$ production have been associated with a variety of human cancer types (reviewed in $[1,18,36,37]$ ). However, understanding how these epigenetic changes directly contribute to the malignant phenotype has been elusive. Furthermore, TGF $\beta$ pathway antagonists that either target the ligand or receptor kinases are in clinical development (reviewed in [24, 38-41]). In either case, it is essential to determine how and to which degree the TGF $\beta / \mathrm{Smad}$ signaling can best be inhibited to achieve the desired therapeutic effect.

Using immortalized human keratinocytes as our experimental model, we varied the TGF $\beta$ signal by reducing T $\beta$ R-I receptor kinase activity using a selective chemical competitive inhibitor of the enzyme as well as by comparing 
tive inhibitor of the enzyme as well as by comparing endogenous TGF $\beta /$ Smad signaling with the effects induced by high levels of exogenous TGF $\beta$. Treatment of cells with receptor-saturating doses of exogenous TGF $\beta$ induced or repressed approximately 200 different genes in a T $\beta R$-Idependent manner (Supplementary Material). These results are consistent with several previous reports [32-34, 42]. Of the 92 genes previously identified in at least two different human epithelial cell lines, 51 were represented in the current study (Table 1). This is reassuring and inspires confidence in the validity of our results. In aggregate, studies of exogenous TGF $\beta$-regulated genes in human epithelial cells have consistently identified a core signature of approximately 50 genes that are regulated by high doses of this cytokine (Table 1)[43]. These include genes involved in development, regulation of biological processes, cell growth, and the cellular response to external noxious stimuli (Supplementary Material).

Our results indicate that different subsets of genes can be distinguished on the basis of the kinetics of TGF $\beta$-mediated activation or repression (Fig. 4, Supplementary Material). This result is also consistent with a number of previous reports [33, 44-50]. To explain the differences in kinetics between different gene sets, Yang et al. [47] proposed the model that the initial wave of TGF $\beta$-regulated genes drives the activation/repression of the secondary and tertiary waves of genes. Consistent with this hypothesis, we also found the early- and intermediate gene groups to predominantly encode transcription factors, signal transducers and enzymes, while the late gene group predominantly encoded molecules involved in receptor-protein and protein-protein interactions (not shown). In addition, we found that the magnitude of gene expression change induced by TGF $\beta$ decreased with each successive wave of target genes. This novel observation is entirely consistent with the proposed hierarchical model of gene regulation [47].

Perhaps the most important result of our study is that attenuation of TGF $\beta$ receptor signaling and different ligand levels each result in substantive but quite distinct changes in cellular responses in terms of the spectrum and kinetics of gene regulation, and the degree to which different cellular processes are affected. Our studies demonstrated that the gene expression program activated by a high level of exogenous TGF $\beta$ is significantly broader than that engaged by endogenous TGF $\beta$. In addition, only approximately one third of the transcripts regulated by endogenous TGF $\beta$ were represented within the (larger) set of exogenous TGF $\beta$-regulated genes. Thus, exposing cells to low levels of TGF $\beta$ affects a much narrower and, to a large extent, qualitatively distinct spectrum of genes than treatment with high doses of TGF $\beta$. This result is reminiscent of those obtained with embryonic stem cell (ESC)-derived endothelial cells by Watabe et al. [51]. These investigators noted that treatment of ESCderived endothelial cells with a chemical T $\beta$ R-I kinase inhibitor resulted in a dose-dependent reduction in basal $\mathrm{pSmad} 2$ levels and an increase in size and integrity of endothelial sheets, while treatment with a TGF $\beta$ neutralizing antibody (which selectively neutralizes free TGF $\beta$ in the culture medium) had no effect. Thus, in this case, endogenous TGF $\beta$ signaling suppressed cell proliferation [51]. In contrast, higher concentrations of TGF $\beta$ induced phosphorylation of Smad1 and -5 , cell migration and capillary sprouting
[51-53]. In aggregate, these observations are consistent with the hypothesis that endogenous TGF $\beta$ signaling is primarily involved in maintaining tissue homeostasis, while treatment of cells with high levels of TGF $\beta$ mimics the physiological response of epithelia or endothelia to tissue injury, which is associated with a time- and space-limited burst of TGF $\beta$ activation [54].

Besides the fact that variations in TGF $\beta$ dosage were associated with major changes in gene expression profiles, attenuation of TGF $\beta$ receptor signaling using a chemical receptor kinase inhibitor also resulted in substantive changes in both the magnitude and kinetics of TGF $\beta$-mediated gene expression signatures as well as in cellular responses. Attenuating T $\beta R$-I kinase activity most strongly inhibited the effects of high dose TGF $\beta$ on the set of late genes, while the early and intermediate genes were relatively unaffected. Similarly, Lindemann et al. [55] reported that treatment of human breast carcinoma cells with the T $\beta$ R-I kinase inhibitor, SB-203580, attenuated the TGF $\beta$-mediated induction of intermediate or late transcripts to a greater extent than the early transcript, SMAD7. Even though SB-203580 is a far less selective T $\beta R$-I inhibitor than SD-093, and only a limited number of transcripts were analyzed, these results are consistent with our own. It is important to note that the late genes, which were the most sensitive to a reduction in T $\beta R$-I signal capability, included the ones involved in cell growth regulation. This finding is in accord with our observation that TGF $\beta$-mediated growth inhibition is exquisitely sensitive to interference by the TRR-I inhibitor, while EMT (which includes cell motility) appears to be less sensitive (Figs. 1, 2). Moreover, these findings provide further support for the model that the two major physiological functions of TGF $\beta$ (maintenance of tissue homeostasis and response to tissue injury) are invoked by different levels of activation of the TGF $\beta / T \beta R-I / S m a d$ signaling pathway. Consistent with this idea, Chen et al. [56] demonstrated that cells, in which the level of endogenous wild type T $\beta$ R-II receptor was reduced while T $\beta R$-I remained constant, no longer responded to TGF $\beta$-mediated growth inhibition, while the induction of SERPINE1, FN1 and JUNB mRNA were unaffected. Thus, the ratio of available type II versus type I receptors may be the critical determinant of response specificity. Consistent with this putative T $\beta$ R-II/I threshold model, Peng et al. [57] utilized T $\beta$ R-I receptor selective aryl-substituted pyrazoles to demonstrate that extracellular matrix protein induction by TGF $\beta$ in normal epithelial cells requires a higher level of T $\beta R$-I kinase activity than cell growth inhibition.

\section{CONCLUSION}

Our results have two major implications that are illustrated by the model depicted in Fig. (8). First, our model helps clarify the complex changes that TGF $\beta$ signaling undergoes during cancer development. Many cancers have been associated with significant reductions in T $\beta R$ receptor levels. Our findings support the idea that a quantitative reduction in the level of receptor expression or activity eliminates a set of genes from the TGF $\beta$-regulated transcriptional program that are primarily involved in maintaining homeostasis and development. Interestingly, the developmental genes are primarily those that control vascular development. In this context, one might speculate that germline T $\beta R$ receptor mutations that cause the development of aortic aneurysms 
at a young age $[58,59]$ may be associated with a loss of this same genetic program. On the other hand, a subset of endogenous TGF $\beta$-dependent genes that is relatively insensitive to T $\beta R$ blockade continues to be expressed. When, as is often the case in advanced cancers, the level of active TGF $\beta$ within the tumor microenvironment becomes elevated, a third genetic program becomes activated that is primarily involved in the cellular response to noxious external stimuli, including stress, infection and injury. This gene set includes a large number of chemokines, cytokines, cytokine regulators, matrix metalloproteases and mediators of inflammation that play key roles in invasion, tumor angiogenesis and metastasis [60-63]. In summary, our working model is that two major changes in TGF $\beta$ signaling occur during tumor development: the first is associated with a global reduction in receptor signaling and results in loss of homeostatic control and of TGF $\beta$ 's tumor suppressive activity, while the second is associated with overproduction of bioactive TGF $\beta$, resulting in activation of a pro-invasive, -angiogenic, and metastatic TGF $\beta$-regulated gene expression program (Fig. 8).

Our studies also have major implications for the optimal use of TGF $\beta$ pathway antagonists as anti-cancer therapeutics [24]. Our results indicate that TGF $\beta$-mediated inhibition of cell growth requires a much lower concentration of TGF $\beta$ and is much more sensitive to blockade by TGF $\beta$ receptor antagonists than the induction of EMT and cell motility. Assuming that EMT is a reliable in vitro biomarker for cell invasion in vivo, these results predict that achieving antiinvasive or -metastatic activity may require much higher doses of TGF $\beta$ antagonists than would be required to abrogate TGF $\beta$ 's homeostatic function. Conversely, underdosing these agents might substantially negate their therapeutic efficacy, as this would abrogate TGF $\beta$ 's tumor suppressive function without achieving the therapeutic benefit of anticancer activity. Moreover, as our results show that partial reductions of either T $\beta$ R-I kinase activity or TGF $\beta$ levels have very distinct effects, a second prediction is that the two main classes of TGF $\beta$ antagonists, i.e. those that target the ligand and those that inhibit receptor kinases, are likely to have very distinct effects on the gene expression program and, by extension, on the cellular phenotype: Specifically, ligand antagonists may selectively abrogate the effects that are uniquely induced by high levels of TGF $\beta$ (response to external stimuli genes), while receptor kinase inhibitors would abrogate the entire gene expression program, including TGF $\beta$ 's effects on development and homeostasis. If this prediction is correct, chronic treatment with ligand antagonists may turn out to be safer and have a more favorable therapeutic index than inhibiting receptor kinase activity. A definitive answer to this question will have to await the results of clinical trials of both classes of agents that are currently underway.

\section{ABBREVIATIONS}

$\begin{array}{lll}\text { EMT } & = & \text { Epithelial-to-mesenchymal transition } \\ \text { TGF } \beta= & \text { Transforming Growth Factor }-\beta \\ \text { T } \beta \text { R-I }= & \text { TGF } \beta \text { type I receptor } \\ \text { T } \beta \text { R-II }= & \text { TGF } \beta \text { type II receptor }\end{array}$

\section{ACKNOWLEDGEMENTS}

This work was supported, in part, by Public Health Service Awards CA-41556 and CA-94431 to MR from the National Cancer Institute, as well as by the Cancer Center Support Grant CA-72720 from the National Cancer Institute

\section{REFERENCES}

[1] Reiss M. TGF-beta and cancer. Microbes Infect 1999; 1: 1327-47.

[2] Massague J, Chen Y-G. Controlling TGF- $\beta$ signaling. Genes Dev 2000; 14: 627-44.

[3] Yu L, Hebert MC, Zhang YE. TGF-beta receptor-activated p38 MAP kinase mediates Smad-independent TGF-beta responses. EMBO J 2002; 21: 3749-59.

[4] Abdollah S, Macias-Silva M, Tsukazaki T, Hayashi H, Attisano L, Wrana JL. TbetaRI phosphorylation of Smad2 on Ser465 and Ser467 is required for Smad2-Smad4 complex formation and signaling. J Biol Chem 1997; 272: 27678-85.

[5] Souchelnytskyi S, Tamaki K, Engstrom U, Wernstedt C, ten Dijke $\mathrm{P}$, Heldin CH. Phosphorylation of Ser465 and Ser467 in the C terminus of Smad2 mediates interaction with Smad4 and is required for transforming growth factor-beta signaling. J Biol Chem 1997; 272: 28107-15.

[6] Pierreux CE, Nicolas FJ, Hill CS. Transforming Growth Factor beta-Independent shuttling of Smad4 between the cytoplasm and nucleus. Mol Cell Biol 2000; 20: 9041-54.

[7] Xu L, Kang Y, Col S, Massague J. Smad2 nucleocytoplasmic shuttling by nucleoporins CAN/Nup214 and Nup153 feeds TGFbeta signaling complexes in the cytoplasm and nucleus. Mol Cell 2002; 10: 271-82.

[8] Inman GJ, Nicolas FJ, Hill CS. Nucleocytoplasmic shuttling of Smads 2, 3, and 4 permits sensing of TGF-beta receptor activity. Mol Cell 2002; 10: 283-94.

[9] Wu JW, Hu M, Chai J, et al. Crystal structure of a phosphorylated Smad2. Recognition of phosphoserine by the MH2 domain and insights on Smad function in TGF-beta signaling. Mol Cell 2001; 8: 1277-89.

[10] Massague J, Wotton D. Transcriptional control by the TGFß/Smad signaling system. EMBO J 2000; 19: 1745-54.

[11] Attisano L, Wrana JL. Smads as transcriptional co-modulators. Curr Opin Cell Biol 2000; 12: 235-43.

[12] Wakefield LM, Roberts AB. TGF-beta signaling: positive and negative effects on tumorigenesis. Curr Opin Genet Dev 2002; 12 : 22-9.

[13] Reiss M. Transforming Growth Factor- $\beta$ and cancer. In: Gressner AM Ed. Cytokines in Liver Injury and Repair - Falk Symposium 125. Amsterdam: Kluwer Academic Publishers 2002: 73-94.

[14] Piek E, Roberts AB. Suppressor and oncogenic roles of transforming growth factor-beta and its signaling pathways in tumorigenesis. Adv Cancer Res 2001; 83: 1-54.

[15] Massagué J. TGF- $\beta$ signaling: Receptors, transducers, and MAD proteins. Cell 1996; 85: 947-50.

[16] Reiss M, Stash EB. High frequency of resistance of human squamous carcinoma cells to the anti-proliferative action of Transforming Growth Factor-ß. Cancer Commun 1990; 2: 363-9.

[17] de Jonge RR, Garrigue-Antar L, Vellucci VF, Reiss M. Frequent inactivation of the transforming growth factor beta type II receptor in small-cell lung carcinoma cells. Oncol Res 1997; 9: 89-98.

[18] Kim SJ, Im YH, Markowitz SD, Bang YJ. Molecular mechanisms of inactivation of TGFß receptors during carcinogenesis. Cytokine Growth Factor Rev 2000; 11: 159-68.

[19] Wang D, Song H, Evans JA, Lang JC, Schuller DE, Weghorst CM. Mutation and downregulation of the transforming growth factor beta type II receptor gene in primary squamous cell carcinomas of the head and neck. Carcinogenesis 1997; 18: 2285-90.

[20] Fukai Y, Fukuchi M, Masuda N, et al. Reduced expression of transforming growth factor-beta receptors is an unfavorable prognostic factor in human esophageal squamous cell carcinoma. Int $\mathrm{J}$ Cancer 2003; 104: 161-6.

[21] Huse M, Muir TW, Xu L, Chen YG, Kuriyan J, Massague J. The TGF beta receptor activation process: an inhibitor- to substratebinding switch. Mol Cell 2001; 8: 671-82.

[22] Ge R, Rajeev V, Subramanian G, et al. Selective inhibitors of type I receptor kinase block cellular transforming growth factor-beta signaling. Biochem Pharmacol 2004; 68: 41-50. 
[23] Subramanian G, Schwarz RE, Higgins L, et al. Targeting endogenous transforming growth factor beta receptor signaling in SMAD4-deficient human pancreatic carcinoma cells inhibits their invasive phenotype1. Cancer Res 2004; 64(15): 5200-11.

[24] Reiss M. Transforming Growth Factor- $\beta$ in metastasis: In vitro and in vivo mechanisms. In: Jakowlew SB, Ed. Transforming Growth Factor-beta in Cancer Therapy. Totowa, NY: The Humana Press, Inc. 2008: 609-34.

[25] Pirisi L, Creek KE, Doniger J, DiPaolo JA. Continuous cell lines with altered growth and differentiation properties originate after transfection of human keratinocytes with human papillomavirus type 16 DNA. Carcinogenesis 1988; 9: 1573-9.

[26] Liu C, Gaca MD, Swenson ES, Vellucci VF, Reiss M, Wells RG. Smads 2 and 3 are differentially activated by Transforming Growth Factor-beta (TGF-beta ) in quiescent and activated hepatic stellate cells. constitutive nuclear localization of Smads in activated cells is TGF-beta -independent. J Biol Chem 2003; 278: 11721-8.

[27] Yeh KC, Kwan KC. A comparison of numerical integrating algorithms by trapezoidal, Lagrange, and spline approximation. J Pharmacokinet Biopharm 1978; 6: 79-98.

[28] Ashburner M, Ball CA, Blake JA, et al. Gene ontology: tool for the unification of biology. The Gene Ontology Consortium. Nat Genet 2000; 25: 25-9.

[29] Doniger SW, Salomonis N, Dahlquist KD, Vranizan K, Lawlor SC, Conklin BR. MAPPFinder: using Gene Ontology and GenMAPP to create a global gene-expression profile from microarray data. Genome Biol 2003; 4: R7.

[30] Dahlquist KD, Salomonis N, Vranizan K, Lawlor SC, Conklin BR. GenMAPP, a new tool for viewing and analyzing microarray data on biological pathways. Nat Genet 2002; 31: 19-20.

[31] Christiansen JJ, Rajasekaran AK. Reassessing epithelial to mesenchymal transition as a prerequisite for carcinoma invasion and metastasis. Cancer Res 2006; 66: 8319-26.

[32] Kang Y, Chen CR, Massague J. A self-enabling TGFbeta response coupled to stress signaling: Smad engages stress response factor ATF3 for Id1 repression in epithelial cells. Mol Cell 2003; 11: 915 26.

[33] Zavadil J, Bitzer M, Liang D, et al. Genetic programs of epithelial cell plasticity directed by transforming growth factor-beta. Proc Natl Acad Sci USA 2001; 98: 6686-91.

[34] Levy L, Hill CS. Smad4 dependency defines two classes of transforming growth factor $\{$ beta $\}$ (TGF-\{beta $\}$ ) target genes and distinguishes TGF-\{beta $\}$-induced epithelial-mesenchymal transition from its antiproliferative and migratory responses. Mol Cell Biol 2005; 25 : 8108-25.

[35] Kang Y. New tricks against an old foe: molecular dissection of metastasis tissue tropism in breast cancer. Breast Dis 2006; 26: 129-38.

[36] Bierie B, Moses HL. TGF-beta and cancer. Cytokine Growth Factor Rev 2006; 17: 29-40.

[37] Levy L, Hill CS. Alterations in components of the TGF-beta superfamily signaling pathways in human cancer. Cytokine Growth Factor Rev 2006; 17: 41-58.

[38] Dumont N, Arteaga CL. Targeting the TGF beta signaling network in human neoplasia. Cancer Cell 2003; 3: 531-6.

[39] Yingling JM, Blanchard KL, Sawyer JS. Development of TGF-beta signalling inhibitors for cancer therapy. Nat Rev Drug Discov 2004; 3: 1011-22.

[40] Akhurst RJ. Large- and small-molecule inhibitors of transforming growth factor-beta signaling. Curr Opin Investig Drugs 2006; 7: 513-21.

[41] Pinkas J, Teicher BA. TGF-beta in cancer and as a therapeutic target. Biochem Pharmacol 2006; 72: 523-9.

[42] Chen CR, Kang Y, Massague J. Defective repression of c-myc in breast cancer cells: A loss at the core of the transforming growth factor beta growth arrest program. Proc Natl Acad Sci USA 2001; 98: 992-9.
[43] Welm AL. TGFbeta primes breast tumor cells for metastasis. Cell 2008; 133: 27-8.

[44] Jonson T, Heidenblad M, Hakansson P, et al. Pancreatic carcinoma cell lines with SMAD4 inactivation show distinct expression responses to TGFB1. Genes Chromosomes Cancer 2003; 36: 340-52.

[45] Chambers RC, Leoni P, Kaminski N, Laurent GJ, Heller RA. Global expression profiling of fibroblast responses to transforming growth factor-beta1 reveals the induction of inhibitor of differentiation-1 and provides evidence of smooth muscle cell phenotypic switching. Am J Pathol 2003; 162: 533-46.

[46] Coyle B, Freathy C, Gant TW, Roberts RA, Cain K. Characterization of the transforming growth factor-beta 1-induced apoptotic transcriptome in $\mathrm{FaO}$ hepatoma cells. J Biol Chem 2003; 278: 5920-8.

[47] Yang YC, Piek E, Zavadil J, et al. Hierarchical model of gene regulation by transforming growth factor beta. Proc Natl Acad Sci USA 2003; 100: 10269-74.

[48] Valcourt U, Kowanetz M, Niimi H, Heldin CH, Moustakas A TGF-beta and the Smad signaling pathway support transcriptomic reprogramming during epithelial-mesenchymal cell transition. Mol Biol Cell 2005; 16: 1987-2002.

[49] Xie L, Law BK, Aakre ME, et al. Transforming growth factor betaregulated gene expression in a mouse mammary gland epithelial cell line. Breast Cancer Res 2003; 5: R187-98.

[50] Verrecchia F, Chu ML, Mauviel A. Identification of novel TGFbeta /Smad gene targets in dermal fibroblasts using a combined cDNA microarray/promoter transactivation approach. J Biol Chem 2001; 276: 17058-62.

[51] Watabe T, Nishihara A, Mishima K, et al. TGF-beta receptor kinase inhibitor enhances growth and integrity of embryonic stem cell-derived endothelial cells. J Cell Biol 2003; 163: 1303-11.

[52] Goumans MJ, Valdimarsdottir G, Itoh S, et al. Activin receptorlike kinase (ALK)1 is an antagonistic mediator of lateral TGFbeta/ALK5 signaling. Mol Cell 2003; 12: 817-28.

[53] Goumans MJ, Valdimarsdottir G, Itoh S, Rosendahl A, Sideras P, ten Dijke P. Balancing the activation state of the endothelium via two distinct TGF-beta type I receptors. EMBO J 2002; 21: 174353.

[54] Schmid P, Cox D, Bilbe G, et al. TGF-beta s and TGF-beta type II receptor in human epidermis: differential expression in acute and chronic skin wounds. J Pathol 1993; 171: 191-7.

[55] Lindemann RK, Nordheim A, Dittmer J. Interfering with TGFbetainduced Smad3 nuclear accumulation differentially affects TGFbeta-dependent gene expression. Mol Cancer 2003; 2: 20.

[56] Chen RH, Ebner R, Derynck R. Inactivation of the type II receptor reveals two receptor pathways for the diverse TGF-beta activities. Science 1993; 260: 1335-8.

[57] Peng SB, Yan L, Xia X, et al. Kinetic characterization of novel pyrazole TGF-beta receptor I kinase inhibitors and their blockade of the epithelial-mesenchymal transition. Biochemistry 2005; 44: 2293-304.

[58] Loeys BL, Schwarze U, Holm T, et al. Aneurysm syndromes caused by mutations in the TGF-beta receptor. N Engl J Med 2006; 355: 788-98.

[59] Mizuguchi T, Matsumoto N. Recent progress in genetics of Marfan syndrome and Marfan-associated disorders. J Hum Genet 2007; 52: $1-12$.

[60] Aggarwal BB, Shishodia S, Sandur SK, Pandey MK, Sethi G. Inflammation and cancer: how hot is the link? Biochem Pharmacol 2006; 72: 1605-21.

[61] Kaplan RN, Rafii S, Lyden D. Preparing the "soil": the premetastatic niche. Cancer Res 2006; 66: 11089-93.

[62] Ben-Baruch A. Inflammation-associated immune suppression in cancer: the roles played by cytokines, chemokines and additional mediators. Semin Cancer Biol 2006; 16: 38-52.

[63] Neufeld G, Kessler O. Pro-angiogenic cytokines and their role in tumor angiogenesis. Cancer Metastasis Rev 2006; 25: 373-85. 